\title{
Cartilage regeneration in preannealed silk elastin-like co- recombinamers injectable hydrogel embedded with mature chondrocytes in an ex vivo culture platform
}

\author{
Citation for published version (APA): \\ Cipriani, F., Krüger, M., De Torre, I. G., Sierra, L. Q., Rodrigo, M. A., Kock, L., \& Rodriguez-Cabello, J. C. \\ (2018). Cartilage regeneration in preannealed silk elastin-like co-recombinamers injectable hydrogel embedded \\ with mature chondrocytes in an ex vivo culture platform. Biomacromolecules, 19(11), 4333-4347. \\ https://doi.org/10.1021/acs.biomac.8b01211
}

DOI:

10.1021/acs.biomac.8b01211

Document status and date:

Published: 12/11/2018

\section{Document Version:}

Publisher's PDF, also known as Version of Record (includes final page, issue and volume numbers)

\section{Please check the document version of this publication:}

- A submitted manuscript is the version of the article upon submission and before peer-review. There can be important differences between the submitted version and the official published version of record. People interested in the research are advised to contact the author for the final version of the publication, or visit the DOI to the publisher's website.

- The final author version and the galley proof are versions of the publication after peer review.

- The final published version features the final layout of the paper including the volume, issue and page numbers.

Link to publication

\footnotetext{
General rights

- You may freely distribute the URL identifying the publication in the public portal. follow below link for the End User Agreement:

www.tue.nl/taverne

\section{Take down policy}

If you believe that this document breaches copyright please contact us at:

openaccess@tue.nl

providing details and we will investigate your claim.
}

Copyright and moral rights for the publications made accessible in the public portal are retained by the authors and/or other copyright owners and it is a condition of accessing publications that users recognise and abide by the legal requirements associated with these rights.

- Users may download and print one copy of any publication from the public portal for the purpose of private study or research.

- You may not further distribute the material or use it for any profit-making activity or commercial gain

If the publication is distributed under the terms of Article 25fa of the Dutch Copyright Act, indicated by the "Taverne" license above, please 


\section{Cartilage Regeneration in Preannealed Silk Elastin-Like Co- Recombinamers Injectable Hydrogel Embedded with Mature Chondrocytes in an Ex Vivo Culture Platform}

Filippo Cipriani, ${ }^{* \dagger}$ Melanie Krüger, ${ }^{\star}$ Israel Gonzalez de Torre, ${ }^{\dagger} \S$ Luis Quintanilla Sierra, ${ }^{\S}$ Matilde Alonso Rodrigo, ${ }^{\dagger, \S}$ Linda Kock, ${ }^{\ddagger}$ and José Carlos Rodriguez-Cabello ${ }^{\dagger, \S}$

${ }^{\dagger}$ Technical Proteins Nanobiotechnology S.L., Paseo Belén 9A, 47001 Valladolid, Spain

${ }^{\ddagger}$ LifeTec Group B.V., 5611 ZS Eindhoven, The Netherlands

${ }^{\S}$ Bioforge, University of Valladolid CIBER-BNN, Paseo de Belén 19, 47001 Valladolid, Spain

\section{Supporting Information}

ABSTRACT: Tissue engineering for cartilage repair requires biomaterials that show rapid gelation and adequate mechanical properties. Although the use of hydrogel is the most promising biomaterial, it often lacks in rigidity and anchorage of cells when they are surrounded by synovial fluid while they are subjected to heavy loads. We developed and produced the Silk Elastin-Like co-Recombinamer (SELR), which contains both the physical interaction from elastin motifs and from silk motifs. In the first part of this work, we set up and optimized a preannealing treatment based on the evolution of silk motifs into $\beta$-sheet structures in order to fulfill the required mechanical properties of hydrogels for cartilage repair. The new preannealed SELRs $\left(\mathrm{pA}(\mathrm{EIS})_{2}-\left(\mathrm{I}_{5} \mathrm{R}\right)_{6}\right)$ were characterized with the combination of several experimental techniques $(\mathrm{CD}$, TEM, SEM, and rheology) to provide a deep insight into the material features. Finally, the regeneration properties of the $\mathrm{pA}(\mathrm{EIS})_{2}-\left(\mathrm{I}_{5} \mathrm{R}\right)_{6}$ hydrogel embedded with chondrocytes were evaluated. After 4 weeks of culturing in a standardized and representative ex vivo model, the biochemical and histological analysis revealed the production of glycosaminglycans and collagen. Moreover, the immunohistochemistry showed the absence of fibro-cartilage and the presence of hyaline cartilage. Hence, we conclude that the $\mathrm{pA}(\mathrm{EIS})_{2}-\left(\mathrm{I}_{5} \mathrm{R}\right)_{6}$ hydrogel presents improved mechanical properties while conserving the injectability, which leads to successful regeneration of hyaline cartilage in an ex vivo model.

\section{INTRODUCTION}

Articular cartilage is central to the proper functioning of synovial joints. It covers the opposing articulating bones, and through its properties of high resiliency and deformability, it protects them from compressive joint loads. ${ }^{1}$ Moreover, it provides a smooth and gliding surface with a very low coefficient of friction. ${ }^{2}$ Many people suffer from cartilage degeneration due to genetic abnormalities, trauma, or osteoarthritis. ${ }^{3}$ One of the main issues in this regard is that articular cartilage possesses limited regeneration ability because of its avascular character and the fact that only one cell type (chondrocytes) is present. ${ }^{4,5}$

Because of the absence of self-repair abilities, various surgical interventions and biomaterials have been explored to facilitate regeneration of cells and cartilaginous matrix. ${ }^{5}$ The physical properties of the extra cellular matrix (ECM) often refer to its rigidity, porosity, insolubility, topography, and other characteristics that are essential for its scaffolding role in supporting tissue structure and integrity, and for its role in migration and anchorage of the cells. ${ }^{6}$ Moreover, another important parameter to take into account is the permeability of cartilage; it contributes to several tissue functions like the transport of nutrients to chondrocytes, the ability to carry heavy loads, and the maintenance of a lubricating fluid film between opposing articular surfaces. ${ }^{7}$ Permeability is a measure of the ability of fluid to flow through a porous-permeable material, such as an ECM, and is inversely proportional to the friction drag exerted by the fluid. ${ }^{8}$ The low permeability of articular cartilage prevents fluid from being quickly squeezed out of the matrix. ${ }^{9}$

The purpose of surgery is the regeneration of the chondral defects to ultrastructural and biomechanical competent hyaline cartilage. From a scientific point of view, the clinical treatments are limited in their ability to functionally regenerate cartilage defects, as they often result in the formation of fibrotic tissue, which consists mainly of collagen type I and is therefore mechanically inferior to native cartilage.

Biomaterials with an elastic modulus in the range of $1-10$ $\mathrm{kPa}$ are of widespread interest, as many native tissues also have

Received: August 10, 2018

Revised: October 9, 2018

Published: October 12, 2018 
moduli in this range. ${ }^{10,11}$ The hydrogels developed to repair joint cartilage are more effective when their stress relaxation behavior matches with the native tissue because such behavior affects load transfer and nutrient transport. ${ }^{12,13} \mathrm{Up}$ to $80 \%$ of articular cartilage wet weight consists of water. ${ }^{14}$ To replicate this environment, hydrogels have become a popular option for cartilage regeneration in situ and cartilage engineering in vitro. ${ }^{19-17}$ The purpose of these types of scaffold is not only to provide support for cell attachment and spreading but also to have mechanical stability at the defect site; although, it is important to take into account that the aim of these scaffolds is not to substitute for the tissue but to improve cartilage regeneration in order to obtain a mature tissue.

Natural polymers such as collagen and hyaluronic acid have some limitations: for instance, the insufficient mechanical integrity and the short lifetime in inflamed defects due to degradation by matrix metalloproteinases. ${ }^{18}$ From a biological point of view, the major drawback of synthetic polymer hydrogels such as polyglycolic acid (PGA) and polylactide acid (PLA) is that they do not provide specific biological functions. ${ }^{19}$ Moreover, synthetic polymer hydrogels do not fully recapitulate the chemical and biological features of ECM, considering that they generally regenerated fibro cartilage instead of hyaline cartilage. ${ }^{20}$

Over the last few decades, recombinant DNA techniques have proven to be very powerful tools for the development of novel protein-based biomaterials that are able to self-assemble into different structures, such as hydrogels. ${ }^{21}$ These biomaterials include elastin-like recombinamers (ELRs), which are protein based polypeptides that comprise repetitive units of the Val-Pro-Gly-X-Gly (VPGXG) ${ }_{n}$ pentapeptide, in which $\mathrm{X}$ (guest residue) could be any amino acid except L-proline. Moreover, they show thermoresponsiveness due to the change of the protein conformation above the so-called transition temperature $\left(T_{t}\right)$, which itself depends on the amino acid composition of the polymer. ${ }^{22}$ Therefore, taking into account two ELRs with the same amino acid composition except for the guest amino acid, the $T_{t}$ can be tuned depending on the polarity of the side chain for the guest residue in the $\mathrm{X}$ position of the pentapeptide. ${ }^{23,24}$ Furthermore, ELRs can be designed so the phase transition occurring above the $T_{t}$ is translated into a hydrophobically driven self-assembly of the molecules toward supramolecular hydrogels. ${ }^{25}$

In this work, we have used previously described amphiphilic Silk-Elastin-Like co-Recombinamers (SELR) ${ }^{26,27}$ including two types of elastin-like domains, one hydrophilic and the other one hydrophobic. SELR also contains the amino acid sequences derived from other structural proteins like the GAGAGS hexapeptide (G: Glycine, A: Alanine, S: Serine) found in Bombyx mori silk fibroin, hence giving rise to SELR. ${ }^{28}$ Furthermore, the final sequence also contains the well-known RGD cell-adhesion sequence, which promotes specific cell attachment via integrins that provide a cell-friendly environment. ${ }^{29}$ This recombinamer contains a dual physical interaction that triggers gel formation, in order to obtain a rapid and stable gel that can be delivered into the area of interest via a simple injection. The elastin motifs have been reported to form elastomeric hydrogels, in which the hydrophilic blocks provide conformational elastic properties, and the hydrophobic blocks form cross-links by hydrophobic aggregation. $^{30,31}$ The silk motifs have been reported to be responsible for the supramolecular rearrangement into $\beta$ sheets, which increases the moduli of the hydrogels. ${ }^{26}$
However, the rearrangement of silk motifs into $\beta$-sheets with the consequent formation of a fibrillary structure takes time; the long time needed represents a drawback in terms of surgical application for the cartilage environment, which is surrounded by synovial fluid.

Furthermore, recent works have demonstrated that physical and structural features of the ECM, such as fibrils, are essential for its scaffolding role in supporting tissue structure and integrity. ${ }^{6,32}$ The nanofiber environment plays an essential role in the migration and anchorage of the cells. Considering that one difficulty in nanofiber technology has been the placement of cells within a nanofibrillar structure, ${ }^{33}$ the purpose of this work is to design a system based on supramolecular selfassembly to form nanofibrillar matrices in situ, around the cells, without cellular damage.

This study focuses on the correlation between the elastin motifs and silk motifs, in order to understand how to improve the gelation properties of the hydrogel to obtain a system capable of forming an ECM fibrillary structure directly after injection. We set up and optimized a thermal treatment (preannealing treatment), which accelerates the $\beta$-sheet formation without losing the injectability of the material. The new $\mathrm{pA}(\mathrm{EIS})_{2}-\left(\mathrm{I}_{5} \mathrm{R}\right)_{6}$ were characterized either with molecular analysis (circular dichroism and transmission electron microscopy) or with rheological characterization, in order to investigate the impact of the preannealing treatment on the arrangement of the silk motifs into $\beta$-sheet conformation. Moreover, the morphology of the hydrogel was checked using scanning electron microscopy in order to verify the interconnected structure and an adequate porosity and permeability.

The incorporation of cells into biomaterial scaffolds include multiple aspects in cartilage repair; thus, considering that cells are the driving force of cartilage formation, they can significantly help orchestrate regeneration and overcome some of the limitations of using cells or biomaterials alone. ${ }^{34}$ The use of mature chondrocytes is based on the premise that native mature cells are best suited to guide regeneration. ${ }^{34}$ Moreover, the remarkable property of ELRs permits a homogeneous embedding of cells in the ELR solution at a temperature below $T_{t}$, while molecules can self-assemble into hydrogels above the $T_{t}$ thus allowing the use of the cellscaffold system in injectable therapies perfectly suitable to the shape of the injured area. ${ }^{35}$ Therefore, although other ELRbased hydrogels have shown a minimal inflammatory response, confirming its high and extraordinary biocompatibility, ${ }^{36}$ we performed an in vitro study evaluating the metabolic activity of the chondrocytes embedded in the 3D hydrogel.

The potential properties of $\mathrm{pA}(\mathrm{EIS})_{2}-\left(\mathrm{I}_{5} \mathrm{R}\right)_{6}$ hydrogel in cartilage repair were evaluated in an ex vivo osteochondral culture platform. ${ }^{37}$ The use of bioreactors has some advantages: first, bioreactors are devices in which biological or biochemical processes develop under a closely monitored and tightly controlled environment. ${ }^{38}$ Second, it must be taken into account that cartilage defect models in rodents and mature rabbits show spontaneous self-repair. ${ }^{39}$ In addition, there are some other disadvantages using an animal model: the limited control over physiological parameters, and the limited possibilities for monitoring and controlling the healing progress from a biological and biomechanical point of view, as well as the high costs of animal care and ethical issues. 39,40 


\section{\begin{tabular}{|l|l|l|l|l|l|l|} 
Hydrophilic & Hydrophobic & Silk & Hydrophilic & Hydrophobic & Silk & RGD
\end{tabular}}

Figure 1. Graphical scheme of the composition of $(\text { EIS })_{2}-\left(I_{5} R\right)_{6}$.

\section{MATERIALS AND METHODS}

$(\mathrm{EIS})_{2}-\left(\mathrm{I}_{5} \mathrm{R}\right)_{6}$ Design. Amino Acid Sequence. MESLLP$\left\{\left[(\mathrm{VPGVG})_{2} \text {-VPGEG-(VPGVG) }\right)_{2}\right]_{10^{-}}\left(\mathrm{VGIPG}_{60}-[\mathrm{V}(\mathrm{GAG}-\right.$ AGS $\left.)_{5} \mathrm{G}\right]_{2}-\left[(\text { VPGIG })_{5} \text {-AVTGRGDSPASSV }\right]_{6}$

The composition of this (EIS $)_{2}-\left(I_{5} R\right)_{6}$ is based on previously synthesized block corecombinamers, which have silk-like motifs (SELR). ${ }^{26,41}$ The original block copolymer was designed to comprise a hydrophobic block (containing isoleucine as the guest residue) with a low $\mathrm{T}_{\mathrm{t}}$ and a hydrophilic block (containing glutamic acid with a carboxylic group) with a high $\mathrm{T}_{\mathrm{t}^{*}}{ }^{27}$ The final composition was further functionalized to include RGD cell-adhesion sequences (Figure 1). Initial SELRs were kindly provided by Technical Proteins Nanobiotechnology.

ELR Biosynthesis and Purification. The cloning and molecular biology for gene construction of $(\mathrm{EIS})_{2}-\left(\mathrm{I}_{5} \mathrm{R}\right)_{6}$ were performed using standard genetic-engineering methods. Production was carried out using recombinant techniques with Escherichia coli as the cell system, as described previously. ${ }^{42-45}$ Purification was performed using several cooling and heating purification cycles (Inverse Transition Cycling) following centrifugation.

Pre-Annealing Treatment. The lyophilized recombinamer was dissolved in ultrapure water at a concentration of $50 \mathrm{mg} / \mathrm{mL}$, and incubated at $37^{\circ} \mathrm{C}$ for different time points: $12,24,36$, and $48 \mathrm{~h}$. The $50 \mathrm{mg} / \mathrm{mL}$ concentration for the preannealing treatment was selected considering the inability to form a gel even when using a long incubation time (up to $48 \mathrm{~h}$ ). Afterward, the solution was frozen and the polymer lyophilized again to finally obtain the preannealed SELRs:pA(EIS) $)_{2}-\left(\mathrm{I}_{5} \mathrm{R}\right)_{6}$. The purity and molecular weight of the ELRs were verified by sodium dodecyl sulfate polyacrylamide gel electrophoresis (SDS-PAGE), and matrix-assisted laser desorption/ ionization time-of-flight (MALDI-TOF) mass spectroscopy using a Voyager STR apparatus from Applied Biosystems. Amino acid composition analysis was also performed. Additional characterization of ELRs was accomplished using infrared spectroscopy (FTIR), differential scanning calorimetry (DSC), and nuclear magnetic resonance (NMR) techniques ${ }^{46}$ (Supporting Information Figures S1-S5).

Circular Dichroism (CD). Circular dichroism is an excellent method for rapidly evaluating the secondary structure and folding of proteins. ${ }^{47}$ It is known that the ELR conformational state is temperature-dependent as a consequence of the ITT (inverse temperature transition) behavior experienced by this class of molecules. ${ }^{41}$ For performing $\mathrm{CD}$ experiments, recombinamers $(\mathrm{EIS})_{2}-\left(\mathrm{I}_{5} \mathrm{R}\right)_{6}$ and $\mathrm{pA}(\mathrm{EIS})_{2}-\left(\mathrm{I}_{5} \mathrm{R}\right)_{6}$ were dissolved at a final concentration of $1 \mathrm{mg} / \mathrm{mL}$ and were kept overnight at $4{ }^{\circ} \mathrm{C}$. Just before performing each measurement, a 1:10 dilution was made. The CD spectrum was acquired using a Jasco J-815 150-S spectrometer (Servicios Centrales de Investigación, University of Almeria). A quartz cuvette with a path length of $0.1 \mathrm{~cm}$ was used. The scans were obtained over the wavelength range of $190-260 \mathrm{~nm}$ at the experimental temperatures of 4,37 , and $60{ }^{\circ} \mathrm{C}$ by acquiring points every $0.5 \mathrm{~nm}$ using a scan speed of $50 \mathrm{~nm} / \mathrm{min}$. Before each measurement, samples were equilibrated for $15 \mathrm{~min}$. Spectra were corrected by subtraction of the corresponding blank solvent readings. The data was expressed as molar ellipticity $[\theta]$, which was calculated as follows:

$$
[\theta]=\frac{\theta}{d \times M \times 10}
$$

where $\theta$ is the ellipticity, $d$ is the path length $(\mathrm{cm})$, and $M$ is the concentration (mol/L).

Transmission Electron Microscopy (TEM). Nanostructure formation was checked by TEM. Solutions of (EIS $)_{2}-\left(\mathrm{I}_{5} \mathrm{R}\right)_{6}$ and $\mathrm{pA}(\mathrm{EIS})_{2}-\left(\mathrm{I}_{5} \mathrm{R}\right)_{6}$ were prepared by dissolving pure, lyophilized products in Milli-Q water to a concentration of $25 \mu \mathrm{M}$. These solutions were kept at $4{ }^{\circ} \mathrm{C}$ overnight to allow complete dissolution of the proteins. The samples were incubated at $37^{\circ} \mathrm{C}$ for $15 \mathrm{~min}$ and analyzed directly. TEM measurements were performed using a JEOL JEM-1230 electron microscope operating at $120 \mathrm{kV}$. The specimens were prepared by placing a drop of the solution on a plasma-treated carbon-coated copper grid, followed by water evaporation at $37^{\circ} \mathrm{C}$.

Visualization and Characterization of the Sol-Gel Behavior. In order to check the capacity of $\mathrm{pA}(\mathrm{EIS})_{2}-\left(\mathrm{I}_{5} \mathrm{R}\right)_{6}$ to rapidly form hydrogel and to remain stable in an excess of water, the pure recombinamers were dissolved in PBS (Phosphate-buffered saline) at $4{ }^{\circ} \mathrm{C}$ for $16 \mathrm{~h}$ at the concentrations of $100,120,150$, and $180 \mathrm{mg} / \mathrm{mL}$. Once the recombinamers were in a liquid state at $4{ }^{\circ} \mathrm{C}$, they were placed inside an oven at $37^{\circ} \mathrm{C}$ for $15 \mathrm{~min}$, and the sol-gel behavior was qualitatively observed tilting the Eppendorf containing the solution. Afterward the hydrogels were removed and placed in an excess of water at $37^{\circ} \mathrm{C}$.

Rheological Characterization. A strain-controlled AR-2000ex rheometer (TA Instruments) was employed to perform rheological experiments by using parallel plates of nonporous stainless steel $($ diameter $=12 \mathrm{~mm})$.

Oscillatory measurements were carried out in shear deformation mode. The volume of the gel was $150 \mu \mathrm{L}$, a gap higher than $1000 \mu \mathrm{m}$ was always reached after the sample relaxed until equilibrium. Measurements were performed at $37^{\circ} \mathrm{C}$, with the sample temperature being controlled and maintained using a Peltier device.

First, the solution of $\mathrm{pA}(\mathrm{EIS})_{2}-\left(\mathrm{I}_{5} \mathrm{R}\right)_{6}$ dissolved in PBS was placed over the plate at $37^{\circ} \mathrm{C}$, and a time sweep experiment was performed up to $30 \mathrm{~min}$ with $1 \%$ strain amplitudes and a frequency of $1 \mathrm{~Hz}$; in this case, in situ gelation took place. Then, once the time sweep was over, two different measurements were carried out sequentially. First, the dynamic shear modulus was measured as a function of strain by a dynamic strain sweep with amplitudes ranging between $0.01 \%$ and $20 \%$ at a frequency of $1 \mathrm{~Hz}$. This measurement was done to determine the range of strain amplitudes over which the gel exhibited a linear region of viscoelasticity. A second measurement consisted of the dynamic frequency sweep between 0.1 and $50 \mathrm{~Hz}$ at a fixed strain (selected within the hydrogel linear region), with the aim of obtaining the dependence of the dynamic shear modulus and loss factor on the frequency. Rheological evaluation provided the storage modulus $\left(\mathrm{G}^{\prime}\right)$, the loss modulus $\left(\mathrm{G}^{\prime \prime}\right)$, the complex modulus magnitude $\left|\mathrm{G}^{*}\right|,\left(\left|\mathrm{G}^{*}\right|^{2}\right.$ $\left.=\left(\mathrm{G}^{\prime}\right)^{2}+\left(\mathrm{G}^{\prime \prime}\right)^{2}\right)$, and the loss factor $\tan \delta \equiv\left(\mathrm{G}^{\prime \prime}\right) /\left(\mathrm{G}^{\prime}\right)$, where $\delta$ is the phase angle between the applied stimulus and the corresponding response as a function of strain amplitude or frequency.

In order to obtain the evolution of the viscosity of the $\mathrm{pA}(\mathrm{EIS})_{2^{-}}$ $\left(\mathrm{I}_{5} \mathrm{R}\right)_{6}$ solutions with the shear rate, flow measurements were carried out at $4{ }^{\circ} \mathrm{C}$. In this case, a parallel plate of $40 \mathrm{~mm}$ of diameter was used to improve the measurement sensitivity; the corresponding volume of the gel was $1300 \mu \mathrm{L}$. Initially, a conditioning step was accomplished at a constant shear rate of $0.1 \mathrm{~s}^{-1}$ for $1 \mathrm{~min}$. Next, the shear rate was swept from 0.1 to $500 \mathrm{~s}^{-1}$ using a continuous ramp in a logarithmically ascending series of discrete steps. Specifically, 10 points were acquired for each order of magnitude, and the complete measure took $5 \mathrm{~min}$.

Scanning Electron Microscopy (SEM). Scanning electron microscopy was employed to investigate the morphology of the hydrogel. Fully hydrated gels were dropped into liquid nitrogen, physically fractured, and immersed into liquid nitrogen again. Finally, they were freeze-dried. Images of lyophilized hydrogels were obtained by using a FEI Quanta 200 FEG with no prior coating procedures. Pictures were collected by SEM at Landing E of $7.00 \mathrm{keV}$ and Pressure of 0.7 Torr; afterward they were analyzed with Image-J software.

Chondrocyte Isolation. Pig chondrocytes were isolated from knee joints of Dutch Land Raise Hybrid pigs, male or female, 5-7 
months of age, $100-110 \mathrm{~kg}$ live weight. Small cartilage pieces were removed from the cartilage of the knee joints and were digested in a solution of $0.5 \%(\mathrm{v} / \mathrm{v})$ collagenase (PrepoTech) in high-glucose DMEM (supplemented with $10 \%(\mathrm{v} / \mathrm{v})$, fetal bovine serum (FBS; HyClone, (South America) Research grade, GE Healthcare, Eindhoven, NL), 1\% (v/v) penicillin/streptomycin (Lonza, Westburg, Leusden, NL), 1\% (v/v) amphotericin B (Life Technologies, Bleiswijk, NL). Digestion in $8 \mathrm{~mL}$ collagenase solution per gram of cartilage was executed for $16 \mathrm{~h}$ on a roller bank in the incubator. Subsequently, the cells were washed and filtered three times and stored in a cartilage medium until further use. The cartilage medium consisted of high-glucose DMEM medium supplemented with $1 \%$ (v/ v) penicillin/streptomycin, $1 \%(\mathrm{v} / \mathrm{v})$ amphotericin $\mathrm{B}, 1 \mathrm{mM}$ sodium pyruvate (LifeTechnologies, Bleiswijk, NL), $40 \mu \mathrm{g} / \mathrm{mL}$ L-proline (Sigma-Aldrich, Zwijndrecht, NL), $50 \mu \mathrm{g} / \mathrm{mL}$ L-ascorbic acid-2phosphate (Sigma-Aldrich, Zwijndrecht, NL), 1\% (v/v) ITS+ Premix (Corning, Fisher Scientific, Landsmeer, NL), and $100 \mathrm{nM}$ dexamethasone (Sigma-Aldrich, Zwijndrecht, NL).

Hydrogel Formation and Embedding with Chondrocytes. Freeze-dried pA(EIS $)_{2}-\left(\mathrm{I}_{5} \mathrm{R}\right)_{6}$ was dissolved in plain DMEM (Dulbecco's modified Eagle medium; Life Technologies, Bleiswijk, $\mathrm{NL}$ ) for $16 \mathrm{~h}$ at $4{ }^{\circ} \mathrm{C}$ at $120 \mathrm{mg} / \mathrm{mL}$. Afterward, the solution was placed at $37{ }^{\circ} \mathrm{C}$ for $15 \mathrm{~min}$, and the gel was formed. For the hydrogel embedded with chondrocytes $(20$ million cells $/ \mathrm{ml})$, the cells were mixed with the solution of $\mathrm{pA}(\mathrm{EIS})_{2}-\left(\mathrm{I}_{5} \mathrm{R}\right)_{6}$ dissolved in plain DMEM at $4{ }^{\circ} \mathrm{C}$. The mixture was placed at $37{ }^{\circ} \mathrm{C}$ for $15 \mathrm{~min}$, and the cell embedding gel was formed.

Cell Viability Assay. The viability of isolated chondrocytes embedded in $\mathrm{pA}(\mathrm{EIS})_{2}-\left(\mathrm{I}_{5} \mathrm{R}\right)_{6}$ hydrogels at $120 \mathrm{mg} / \mathrm{mL}$ was assessed by measuring the metabolic activity with PrestoBlue assay (A-13261, Invitrogen). Chondrocytes were isolated and mixed into the hydrogel according to the protocol described above. Of each hydrogel condition, $100 \mu \mathrm{L}$ were pipetted into a 24-well Transwell tissue culture plate (Costar, Kennebunk, U.S.A.) in quadruplicate and topped with $2 \mathrm{~mL}$ of cartilage medium. Culture time was 4 weeks at $37{ }^{\circ} \mathrm{C}$ and $5 \% \mathrm{CO}_{2}$. After letting the cells adapt overnight, metabolic activity measurements were conducted on days 0,14 , and 28 . For this purpose, $2 \mathrm{~mL}$ of a solution of cartilage medium containing $10 \%$ PrestoBlue Viability Reagent (Life Technologies, Eugene, U.S.A.) replaced the culture medium and was incubated in darkness for $2 \mathrm{~h}$. Afterward, $100 \mu \mathrm{L}$ of medium from within the Transwell insert, directly above the gel, was pipetted into a black 96-well plate in triplicate, and fluorescence was read out at an excitation wavelength of $560 \mathrm{~nm}$ and an emission wavelength of $590 \mathrm{~nm}$ with a plate reader (CLARIOstar microplate reader, BMG LABTECH GmbH, Ortenberg, D). The cell viability assay is not an end point measurement analysis, and after each measurement, the solution was removed and replaced with $2 \mathrm{~mL}$ of fresh cartilage medium.

In Vitro Study. In order to evaluate the performance of the $\mathrm{pA}(\mathrm{EIS})_{2}-\left(\mathrm{I}_{5} \mathrm{R}\right)_{6}$ hydrogel embedded with chondrocytes, a 4-week in vitro study was conducted. First, silicone cylinders were produced with an inner diameter of $4 \mathrm{~mm}$ and a height of $2 \mathrm{~mm}$, in correspondence to the simulated cartilage defect in the ex vivo study. After autoclaving, these silicone cylinders were attached to the bottom of a 24-well plate. Next, $150 \mu \mathrm{L}$ of the preannealed (EIS $)_{2}-\left(\mathrm{I}_{5} \mathrm{R}\right)_{6}$ hydrogel embedded with chondrocytes (20 million chondrocytes/ $\mathrm{ml}$ ), and the $\mathrm{pA}(\mathrm{EIS})_{2}-\left(\mathrm{I}_{5} \mathrm{R}\right)_{6}$ hydrogel itself (as a control) were pipetted into the cylinders. After a gelation period of $15 \mathrm{~min}$ in the incubator at $37^{\circ} \mathrm{C}$, the cartilage compartment was topped with $3 \mathrm{~mL}$ of cartilage medium. The culture time was 28 days with medium changes every 3-4 days.

Ex Vivo Study. Osteochondral Explant Isolation. Osteochondral explants $(n=12)$ were isolated from knee joints of Dutch Land Raise Hybrid pigs, male or female, 5-7 months of age, $100-110 \mathrm{~kg}$ live weight. The knees were opened in a sterile manner and three explants were drilled from each medial femoral condyle with a dental drill bit of $8 \mathrm{~cm}$ diameter (MF Dental, Mantel, D). The site was cooled with cold, sterile phosphate-buffered saline (PBS; Sigma-Aldrich, Zwijndrecht, NL) with $2 \%(\mathrm{v} / \mathrm{v})$ penicillin/streptomycin and $2 \%(\mathrm{v} / \mathrm{v})$ amphotericin B, and the explants were broken off from the bone with a custom-made tool. Successively, they were sewn to a bone length of $4 \mathrm{~mm}$ and incubated overnight in cartilage medium.

Cartilage Defect Creation, Hydrogel Incorporation, and Culture. To test the regenerative potential of the $\mathrm{pA}(\mathrm{EIS})_{2}-\left(\mathrm{I}_{5} \mathrm{R}\right)_{6}$ hydrogel for cartilage repair, full-depth cartilage defects of $4 \mathrm{~mm}$ diameter were created with a biopsy punch (PFM Medical AG, Cologne, D), and the defect site was cleaned of remaining cartilage with a sharp spoon (MF Dental, Mantel, D) (Figure 2A). These osteochondral explants with

\section{Ex vivo osteochondral culture platform}

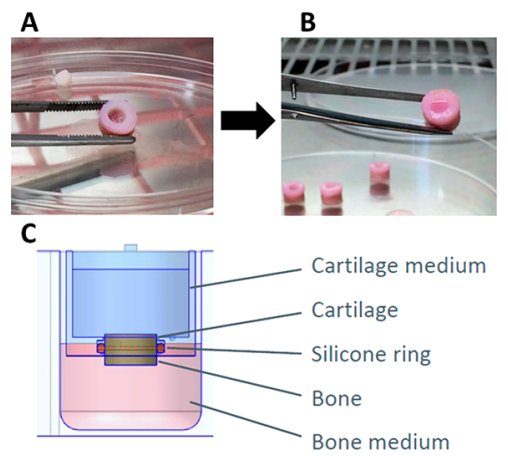

Figure 2. Ex vivo osteochondral culture platform mounting scheme. (A) Creation of the full cartilage defects of $4 \mathrm{~mm}$ diameter with a biopsy punch. (B) Filling of the defects with $30 \mu \mathrm{L}$ of pA(EIS) ${ }_{2}$ $\left(\mathrm{I}_{5} \mathrm{R}\right)_{6}$ hydrogel loaded with 600000 chondrocytes and $30 \mu \mathrm{L}$ of $\mathrm{pA}(\mathrm{EIS})_{2}-\left(\mathrm{I}_{5} \mathrm{R}\right)_{6}$ hydrogel itself (control). (C) Mounting of the explant in the inset with the O-ring situated at the exact interface between the bone and the cartilage.

defects were then mounted in an osteochondral culture platform developed by LifeTec Group BV as previously described. ${ }^{37}$ Briefly, the explants were mounted in an insert with an O-ring situated at the exact interface between the bone and the cartilage (Figure 2C). This insert was then suspended in a custom-made six well plate, thereby resulting in two separate compartments for the bone and the cartilage. By using respective tissue-specific media, complete preservation of native extra cellular matrix composition was achieved over 56 days, thereby allowing regeneration studies in this ex vivo model. Once the explants were mounted in the described way into the inset, the $\mathrm{pA}(\mathrm{EIS})_{2}-\left(\mathrm{I}_{5} \mathrm{R}\right)_{6}$ hydrogel itself (control) and the pA(EIS) $)_{2}-\left(\mathrm{I}_{5} \mathrm{R}\right)_{6}$ hydrogel embedded with chondrocytes $(20$ million chondrocytes $/ \mathrm{ml}$ ) were pipetted into the defects (Figure $2 \mathrm{~B}$ ). In this manner, $30 \mu \mathrm{L}$ of hydrogel itself and $30 \mu \mathrm{L}$ of hydrogel loading 600000 chondrocytes filled each defect. After a gelation period of $15 \mathrm{~min}$ in the incubator at $37^{\circ} \mathrm{C}$, the cartilage compartment was topped with $3 \mathrm{~mL}$ of cartilage medium. The bone compartment was filled with $3 \mathrm{~mL}$ of bone medium consisting of high-glucose DMEM medium supplemented with $10 \%(\mathrm{v} / \mathrm{v})$ FBS, $1 \%(\mathrm{v} / \mathrm{v})$ penicillin/streptomycin, $1 \%(\mathrm{v} / \mathrm{v})$ amphotericin B, $50 \mu \mathrm{g} / \mathrm{mL}$ L-ascorbic acid-2-phosphate, $10 \mathrm{nM} \beta$ glycerophosphate (Sigma-Aldrich, Zwijndrecht, NL), and $100 \mathrm{nM}$ dexamethasone. The medium was changed every 3-4 days, and explants were cultured for 28 days at $37{ }^{\circ} \mathrm{C}$ and $5 \% \mathrm{CO}_{2}$.

Biochemical Analysis. DNA Quantification. The hydrogel samples were carefully and fully removed from the silicone cylinders (for the in vitro study), and from the osteochondral defect (for the ex vivo study) after the respective culturing period. They were then digested by a homogenizer ( $\mathrm{T} 10$ basic Ultra-Turrax IKA) until the gel was completely disrupted. The DNA content was determined by Pico Green assay. Briefly, Pico Green analysis for DNA content was performed in 96-well plates with standard fluorescein wavelengths (excitation: $480 \mathrm{~nm}$ and emission: $520 \mathrm{~nm}$ ) according to the manufacturer's instructions (Invitrogen) using an automated plate reader (Bionova Cientifica, Molecular Devices).

GAG Quantification. GAG content was determined with a modified DMMB (dimethylmethylene blue) assay according to Farndale et al. $^{48}$ After the respective culturing period, the gels were 

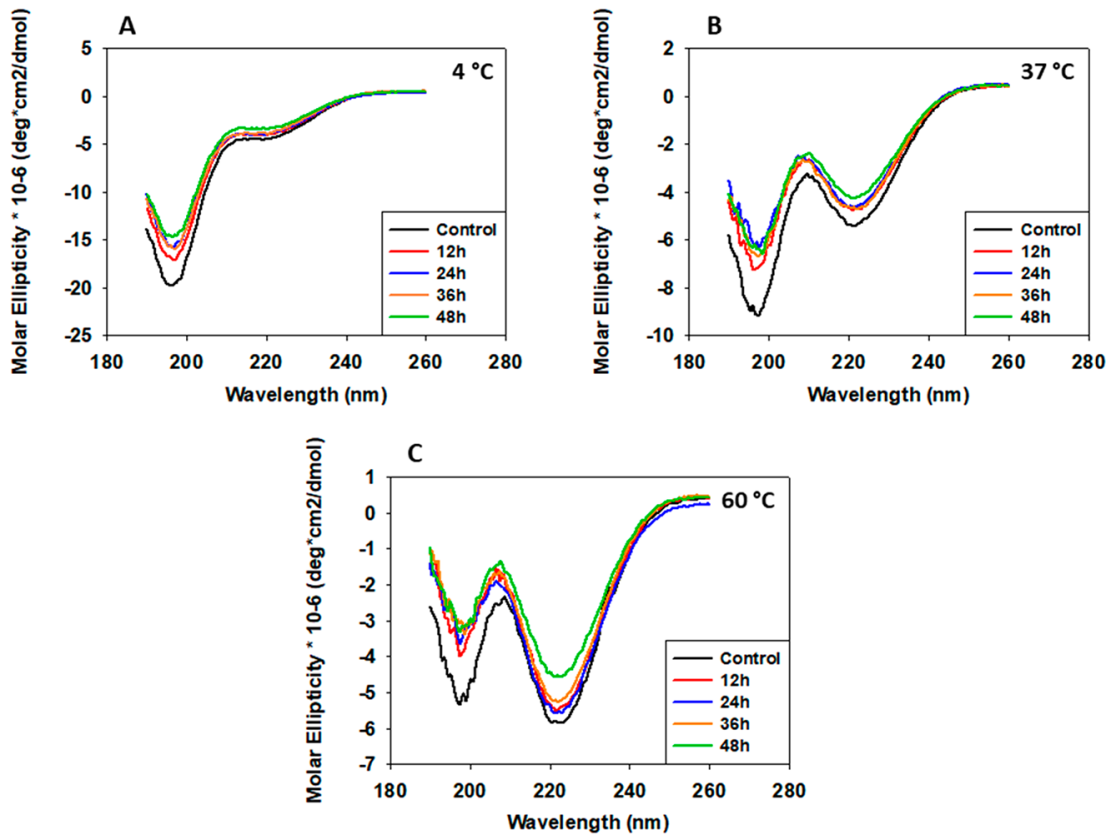

Figure 3. Circular dichroism spectra for $(\mathrm{EIS})_{2}-\left(\mathrm{I}_{5} \mathrm{R}\right)_{6}$ (control) and $\mathrm{pA}(\mathrm{EIS})_{2}-\left(\mathrm{I}_{5} \mathrm{R}\right)_{6}$ with 12,24 , 36, and $48 \mathrm{~h}$ of preannealing time. $\mathrm{CD}$ spectra were recorded for the samples at $0.1 \mathrm{mg} / \mathrm{mL}$ in deionized water. For each sample, $\mathrm{CD}$ spectra were recorded at different temperatures. A: $4{ }^{\circ} \mathrm{C}$; $\mathrm{B}$ : $37^{\circ} \mathrm{C}: \mathrm{C}: 60{ }^{\circ} \mathrm{C}$.

removed, digested, and centrifuged in the same manner as for the DNA analysis. In brief, $40 \mu \mathrm{L}$ of centrifuged samples were pipetted into 96-well plates; the same volume was pipetted for standards, which are a shark cartilage chondroitin sulfate reference (Sigma, Zwijndrecht, NL). Afterward, $150 \mu \mathrm{L}$ of DMMB solution (containing 1-9-dimethylmethylene blue (Sigma-Aldrich, Zwijndrecht, NL)) was added in each well. Immediately afterward, absorbance at 540 and 595 $\mathrm{nm}$ was measured with a plate reader (CLARIOstar microplate reader, BMG LABTECH GmbH, Ortenberg, D), and the GAG concentrations was calculated.

Histological Analysis. For the histological analysis, all the samples were fixed in $4 \%$ formaldehyde in PBS $0.05 \mathrm{M}(\mathrm{pH} 7.3)$ at $4{ }^{\circ} \mathrm{C}$ for about $18 \mathrm{~h}$. Afterward, the samples were dehydrated and infiltrated by paraffin following the automatic procedure performed by the MICROM Tissue Processor. The resulting blocks were cut using a rotary microtome (Leica RM 2125 RTS, Leica Biosystems, Germany) into slices with a thickness of $4 \mu \mathrm{m}$. For general histo-morphological evaluation, the sections were stained with hematoxylin and eosin $(\mathrm{H} /$ E) according to standard protocols. In order to evaluate the collagen and glycosaminoglycan content produced by chondrocytes, the sections were stained with Picro-Sirius Red Stain and Safranin-O/ Fast Green, respectively, according to common methods. Immunohistochemistry for collagen type I and II was performed on $4 \mu \mathrm{m}$ paraffin sections following the manufacturer's instructions and wellestablished protocols. The samples were immunostained with primary antibody mouse monoclonal anticollagen type I (dilution 1:100, Sigma), and with primary antibody mouse monoclonal anticollagen type II (dilution 1:00, Merck), then incubated with the secondary antibody Goat anti Mouse IgG conjugated with HRP (dilution 1:100, abcam). Immunostaining was developed using DAB (Thermo Scientific) followed by hematoxylin counterstaining (Sigma, St. Louis, MO).

Statistical Analysis. Values are expressed as mean \pm standard deviation (SD). The data was examined with a one-way analysis of variance (ANOVA) followed by Tukey's Honestly Significant Difference (HSD) post hoc test. If only two groups were being compared, an unpaired $t$-test was used instead of ANOVA to assess the statistical difference. All statistical analyses were performed with GraphPad Prism. A $P$-value lower than 0.05 was considered statistically significant.

\section{RESULTS}

Circular Dichroism. Circular dichroism (CD) was performed in order to investigate the impact of the preannealing treatment on the $(\mathrm{EIS})_{2}-\left(\mathrm{I}_{5} \mathrm{R}\right)_{6}$ on the consequent arrangement of the silk motifs into $\beta$-sheets. The silk motifs represented around $16 \%$ of the complete sequence of the $(\mathrm{EIS})_{2}-\left(\mathrm{I}_{5} \mathrm{R}\right)_{6}$. The conformational state of ELRs is temperature-dependent as a consequence of the $T_{t}$ behavior experienced by this class of molecules; ${ }^{49}$ thus, the $\mathrm{CD}$ spectra were recorded at different temperatures $\left(4,37\right.$, and $\left.60{ }^{\circ} \mathrm{C}\right)$ in order to verify if such temperature dependence remained operational for $\mathrm{pA}(\mathrm{EIS})_{2}-\left(\mathrm{I}_{5} \mathrm{R}\right)_{6}$ with $12,24,36$, and $48 \mathrm{~h}$ of preannealing time. A sample of $(\mathrm{EIS})_{2}-\left(\mathrm{I}_{5} \mathrm{R}\right)_{6}$ without preannealing was used as a control sample.

At $4{ }^{\circ} \mathrm{C}$ (Figure 3A), an intensely negative band at $197 \mathrm{~nm}$ is displayed for all the curves, which indicates a predominant disordered structure; however, it is possible to see clearly the differences along the curves. The signal of the (EIS $)_{2^{-}}$ $\left(\mathrm{I}_{5} \mathrm{R}\right)_{6}$ (control) reaches lower values compared with the $\mathrm{pA}(\mathrm{EIS})_{2}-\left(\mathrm{I}_{5} \mathrm{R}\right)_{6}$ values with different preannealing times. At this temperature, in the band at $197 \mathrm{~nm}$, a trend is appreciable (corresponding to the preannealing samples) between the 4 curves regarding the different preannealing times. The $12 \mathrm{~h}$ curve values are lower than the 24,36 , and $48 \mathrm{~h}$; moreover, the 24 and $36 \mathrm{~h}$ curves show the same behavior, whereas the $48 \mathrm{~h}$ curve values are higher, showing a more ordered structure. Such a reduced negative band at $197 \mathrm{~nm}$ suggests the presence of a mixture of $\beta$-turns and $\beta$-sheet structures, and agrees with the contribution of elastin and silk moieties to the final conformation. ${ }^{50}$ A shoulder is also present at $4{ }^{\circ} \mathrm{C}$ at $210 \mathrm{~nm}$ for all the curves where the signal of the control reaches lower values compared with the $\mathrm{pA}(\mathrm{EIS})_{2}-\left(\mathrm{I}_{5} \mathrm{R}\right)_{6}$ values with a different preannealing time; all the curves maintain the same trend seen at $197 \mathrm{~nm}$.

At $37{ }^{\circ} \mathrm{C}$ (Figure 3B), the $\mathrm{CD}$ spectra for all the curves clearly displays a less negative signal at $197 \mathrm{~nm}$ compared with 


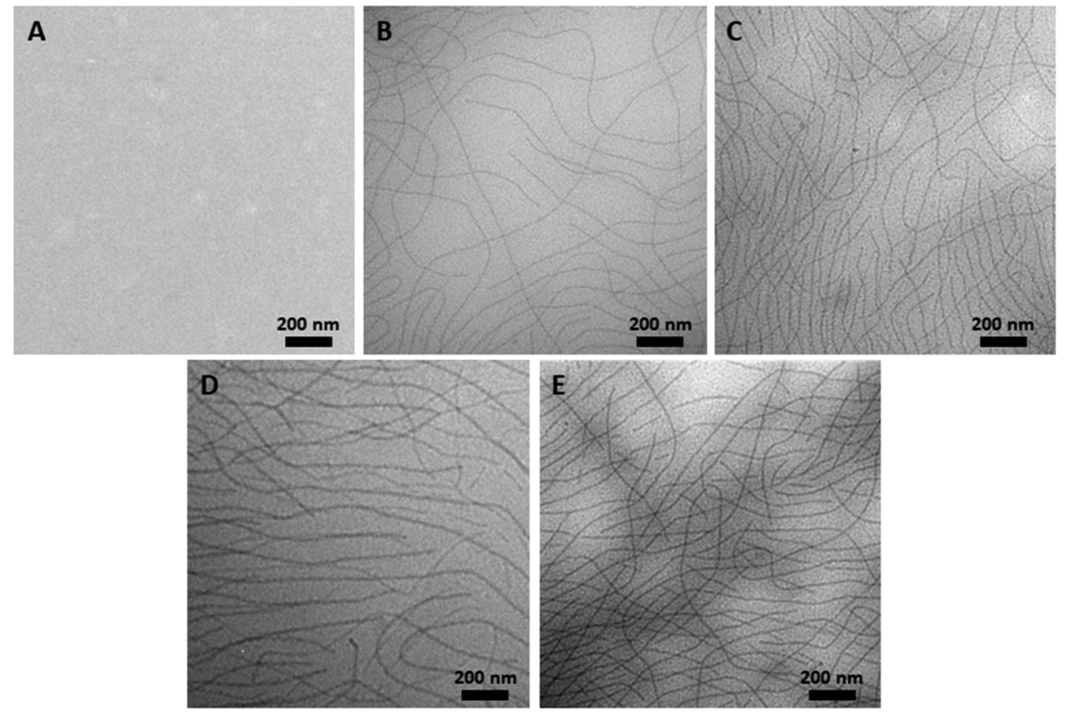

Figure 4. TEM images of the self-assembled nanoparticles formed by (EIS) $)_{2}-\left(\mathrm{I}_{5} \mathrm{R}\right)_{6}$ at the concentration of $25 \mu \mathrm{M}$ in Milli-Q water (A) and $\mathrm{pA}(\mathrm{EIS})_{2}-\left(\mathrm{I}_{5} \mathrm{R}\right)_{6}$ with $12 \mathrm{~h}(\mathrm{~B}), 24 \mathrm{~h}(\mathrm{C}), 36 \mathrm{~h}(\mathrm{D})$, and $48 \mathrm{~h}(\mathrm{E})$ of preannealing time.

$4{ }^{\circ} \mathrm{C}$. Yet, at $37{ }^{\circ} \mathrm{C}$, a clear difference is still present between the control curve and the $\mathrm{pA}(\mathrm{EIS})_{2}-\left(\mathrm{I}_{5} \mathrm{R}\right)_{6}$ curves with different preannealing times. Furthermore, almost no difference is appreciable between the preannealed curves, apart from the $12 \mathrm{~h}$ curve which shows lower values compare to the 24, 36 , and $48 \mathrm{~h}$ curves. Moreover, for all the curves, the magnitude of the signal at $210 \mathrm{~nm}$ increased, and such trend is also maintained when increasing the temperature to higher values $\left(60^{\circ} \mathrm{C}\right)$ (Figure $\left.3 \mathrm{C}\right)$, which suggests the induction of a type II $\beta$-turn conformation with an increase in temperature, as it has previously been observed for EL macromolecules. ${ }^{4,49}$

Finally, also at $60{ }^{\circ} \mathrm{C}$, the $197 \mathrm{~nm}$ values recorded for the control curve are lower compared to the pA(EIS $)_{2}-\left(I_{5} R\right)_{6}$ curves with different preannealing times, which all show similar values.

Transmission Electron Microscopy (TEM). Transmission electron microscopy (TEM) was used to visualize the supramolecular structures comparing $(\mathrm{EIS})_{2}-\left(\mathrm{I}_{5} \mathrm{R}\right)_{6}$ and $\mathrm{pA}$ $(\mathrm{EIS})_{2}-\left(\mathrm{I}_{5} \mathrm{R}\right)_{6}$ with $12,24,36$, and $48 \mathrm{~h}$ of preannealing time. The TEM image for the (EIS $)_{2}-\left(I_{5} R\right)_{6}$ indicated the ability of this SELR to form spherical nanoparticles (Figure 4A). The TEM images for $\mathrm{pA}(\mathrm{EIS})_{2}-\left(\mathrm{I}_{5} \mathrm{R}\right)_{6}$ with $12,24,36$, and $48 \mathrm{~h}$ of preannealing time revealed the emergence of additional and different fibrillary structures (Figure 4B-E). Moreover, a difference is appreciable in the density of the network of fibers between the $12 \mathrm{~h}$ treatment (Figure 4B) and the group of 24, 36 , and $48 \mathrm{~h}$ (Figure 4C,E), where a more dense network of fibers is evident for this group. Thus, the preannealing treatment enhanced the ability of the recombinamer to form a fibrillary structure.

Visualization of the Sol-Gel Behavior. The pure recombinamers $\mathrm{pA}(\mathrm{EIS})_{2}-\left(\mathrm{I}_{5} \mathrm{R}\right)_{6}$ at each preannealing time $(12,24,36,48 \mathrm{~h})$ were dissolved in PBS at $4{ }^{\circ} \mathrm{C}$ for $16 \mathrm{~h}$ at a concentration of $100,120,150$, and $180 \mathrm{mg} / \mathrm{mL}$. Afterward the solutions were placed in an oven at $37{ }^{\circ} \mathrm{C}$ for $15 \mathrm{~min}$. For all the preannealed $(E I S)_{2}-\left(I_{5} R\right)_{6}$ at different annealing times, the lowest concentration possible to form a hydrogel within 15 min was $120 \mathrm{mg} / \mathrm{mL}$ (Figure 5). Moreover, the solution of the $(\mathrm{EIS})_{2}-\left(\mathrm{I}_{5} \mathrm{R}\right)_{6}$ (without preannealing) subjected to the same procedure showed the incapacity to form a stable hydrogel. As it was already demonstrated by Fonseca et al., where the

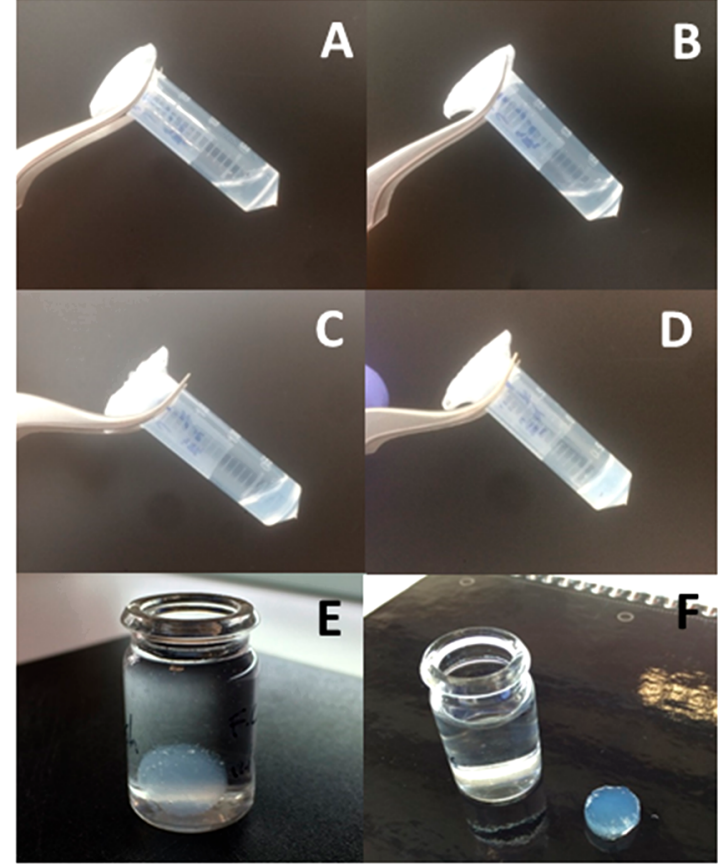

Figure 5. Pictures showing the visualization of the sol-gel behavior. Twenty-four hour $\mathrm{pA}(\mathrm{EIS})_{2}-\left(\mathrm{I}_{5} \mathrm{R}\right)_{6}$ hydrogel at $100 \mathrm{mg} / \mathrm{mL}$ before (A) and after the incubation at $37^{\circ} \mathrm{C}$ for $15 \mathrm{~min}$ (B). Twenty-four hour preannealed $\mathrm{pA}(\mathrm{EIS})_{2}-\left(\mathrm{I}_{5} \mathrm{R}\right)_{6}$ hydrogel at $120 \mathrm{mg} / \mathrm{mL}$ before (C) and after the incubation at $37^{\circ} \mathrm{C}$ for $15 \mathrm{~min}$ (D); finally, the hydrogel was placed in an excess of water (E) showing the ability to remain stable after 1 week at $37{ }^{\circ} \mathrm{C}(\mathrm{F})$.

minimum concentration to form a gel was $145 \mathrm{mg} / \mathrm{mL} .{ }^{27}$ In order to verify the stability of the hydrogel, identical parameters to our application were selected (see Hydrogel Formation and Embedding with Chondrocytes in Materials and Methods). The hydrogel at $120 \mathrm{mg} / \mathrm{mL}$ was placed in an excess of water and showed the ability to remain stable after 1 week at $37{ }^{\circ} \mathrm{C}$ (Figure 5E,F).

Characterization of the Sol-Gel Behavior. In order to understand the driving force of the gelation of the $\mathrm{pA}(\mathrm{EIS})_{2}$ $\left(I_{5} R\right)_{6}$, a rheology study was performed. First of all, an in situ 

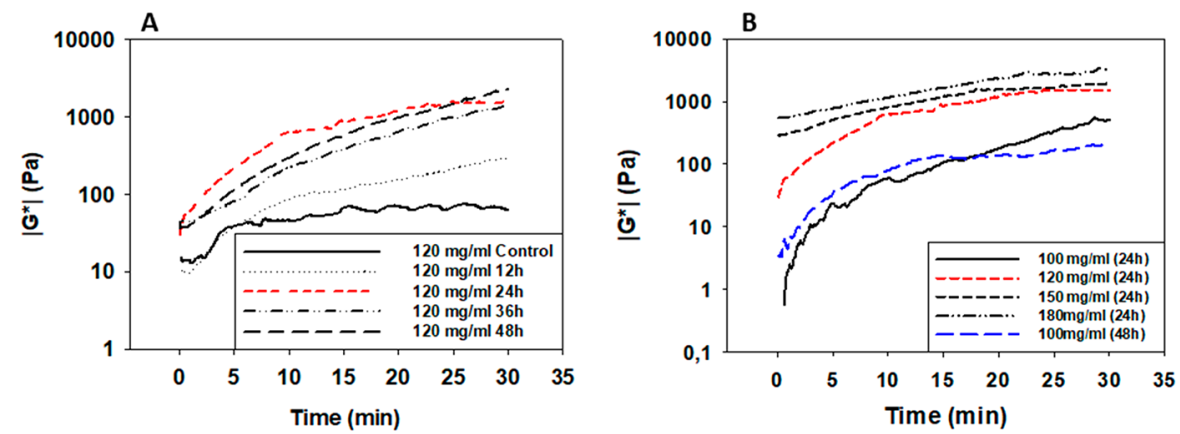

Figure 6. Time sweep measurement at $37{ }^{\circ} \mathrm{C}$ for (A): (EIS $)_{2}-\left(I_{5} \mathrm{R}\right)_{6}$ and $\mathrm{pA}(\mathrm{EIS})_{2}-\left(\mathrm{I}_{5} \mathrm{R}\right)_{6}$ hydrogels at $120 \mathrm{mg} / \mathrm{mL}$ with 12 , 24, 36, and $48 \mathrm{~h}$ of preannealing; (B): pA(EIS $)_{2}-\left(I_{5} R\right)_{6}$ hydrogels with $24 \mathrm{~h}$ of preannealing at $100,120,150$, and $180 \mathrm{mg} / \mathrm{mL}$, and pA(EIS) $)_{2}-\left(I_{5} \mathrm{R}\right)_{6}$ hydrogel with 48 $\mathrm{h}$ of preannealing at $100 \mathrm{mg} / \mathrm{mL}$.

gelation experiment was carried out for a solution of $120 \mathrm{mg} /$ $\mathrm{mL}$. The solutions dissolved in PBS at $4{ }^{\circ} \mathrm{C}$ for $16 \mathrm{~h}$ were placed in the rheometer plate at $37^{\circ} \mathrm{C}$, where a time sweep experiment was carried out for $30 \mathrm{~min}$ (Figure 6A). The complex modulus increased with time in agreement with the study performed by Colino et al. ${ }^{26}$ As can be seen, a clear difference is present between the (EIS $)_{2}-\left(\mathrm{I}_{5} \mathrm{R}\right)_{6}$ curve (control) and the $\mathrm{pA}(\mathrm{EIS})_{2}-\left(\mathrm{I}_{5} \mathrm{R}\right)_{6}$ curves with different preannealing times. Along the preannealing conditions, no noticeable differences were observed in the complex modulus for the preannealing times of 24,36, and $48 \mathrm{~h}$ at the end of the measuring time (around $1 \mathrm{kPa}$ ). Yet, a final complex modulus around $200 \mathrm{~Pa}$ was found for a preannealing time of $12 \mathrm{~h}$.

Therefore, the preannealing time of $24 \mathrm{~h}$ was selected, and several concentrations were considered $(100,120,150$, and $180 \mathrm{mg} / \mathrm{mL}$ ) (Figure 6B). A clear difference was observed between the concentration of $100 \mathrm{mg} / \mathrm{mL}$ and the rest of the concentrations, in agreement with the sol-gel behavior qualitatively observed in Figure 5.

Finally, the effect of the preannealing time for different concentrations can be found in Figure $6 \mathrm{~B}$, where the concentration of $100 \mathrm{mg} / \mathrm{mL}$ was preannealed for $48 \mathrm{~h}$. It could be expected to find similar modulus for samples preannealed for $48 \mathrm{~h}$ at a concentration of $100 \mathrm{mg} / \mathrm{mL}$ and for samples preannealed for $24 \mathrm{~h}$ at a concentration of $120 \mathrm{mg} /$ $\mathrm{mL}$, considering that the lower concentration could be compensated by longer times of preannealing. Instead, as can be seen, the curves of $100 \mathrm{mg} / \mathrm{mL}$ for 24 and $48 \mathrm{~h}$ in Figure 6B are similar, and a lower complex modulus was obtained with respect to the concentration of $120 \mathrm{mg} / \mathrm{mL}$ preannealed for 24 h.

Therefore, the concentration of $120 \mathrm{mg} / \mathrm{mL}$ preannealed for $24 \mathrm{~h}$ presents a threshold for gelation, and these conditions were selected as the most suitable candidate for an injectable hydrogel for cartilage repair.

Viscosity Measurements of the Solutions. Rheological flow measurements were carried out in order to find the evolution of the viscosity of the preannealed $(E I S)_{2}-\left(I_{5} R\right)_{6}$ dissolutions with the shear rate. Since viscosity is the resistance of a fluid to flow upon the application of stress, the viscosity value and its dependence on shear rate provide some insight about the interactions between the micro/nanostructures in our dissolution. These measurements provide some insight into the injectability of the solutions of $120 \mathrm{mg} / \mathrm{mL}$ for different preannealing times. To guarantee injectability, the solution should be of sufficiently low viscosity to allow the use of a small-gauge needle. ${ }^{51}$
In Figure 7, the dependence of the viscosity on the shear rate has been plotted in a lin-log scale for the control sample

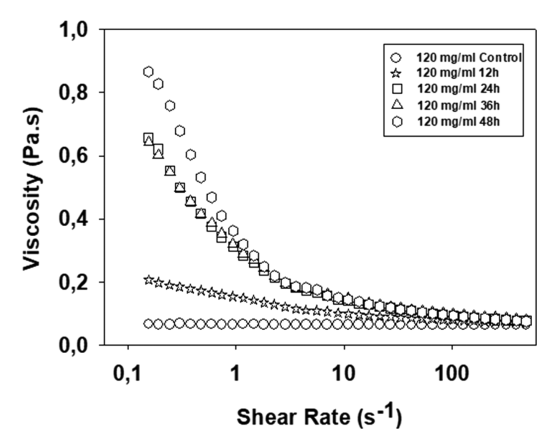

Figure 7. Dependence of the viscosity on the shear rate in a scale lin$\log$ for $(\mathrm{EIS})_{2}-\left(\mathrm{I}_{5} \mathrm{R}\right)_{6} \& \mathrm{pA}(\mathrm{EIS})_{2}-\left(\mathrm{I}_{5} \mathrm{R}\right)_{6}$ hydrogels with $12,24,36$, and $48 \mathrm{~h}$ of preannealing. These parameters were calculated by numerical fitting of the experimental data to eq 1 . In each fitting, $R^{2}>$ 0.990 was found.

(without annealing), and for four preannealed samples at several annealing times $(12,24,36$, and $48 \mathrm{~h})$. As can be seen, when the shear rate is higher than $200-300 \mathrm{~s}^{-1}$, all the curves overlap on a viscosity value around $70-80 \mathrm{mPa} \cdot \mathrm{s}$. Yet, a significantly different evolution of the viscosity is observed in the shear rate range of $0.1-50 \mathrm{~s}^{-1}$. Whereas no evolution of the viscosity with the shear rate is observed for the control sample (Newtonian fluid), the annealed samples show a decrease of the viscosity (shear thinning) with an evident linear dependence of the viscosity in the lin-log scale. Specifically, two slopes are detected in the experimental data.

On the contrary, as can be seen in Figure S6 in Supporting Information (SI) obtained for an identical recombinamer lacking the silk motifs, no dependence of the viscosity with the shear rate for any annealing time was detected.

A noticeable difference was observed in the viscosity of samples for 24, 36, and $48 \mathrm{~h}$ with respect to the sample for 12 h (Figure 7 ). The viscosity for the sample at $48 \mathrm{~h}$ was slightly higher than that of the samples at 24 and $36 \mathrm{~h}$. This trend for $\mathrm{pA}(\mathrm{EIS})_{2}-\left(\mathrm{I}_{5} \mathrm{R}\right)_{6}$ with different annealing time corroborates the behavior recorded with $\mathrm{CD}$ for at $4{ }^{\circ} \mathrm{C}$ (Figure $3 \mathrm{~A}$ ).

Thus, from the viewpoint of injectability, the preannealing time of $24 \mathrm{~h}$ seems to be the most appropriate, considering the sufficient maturation of the $\beta$-sheet structures and an adequate viscosity to make the injection process easier.

Rheological Characterization of the Hydrogels. Immediately after the $30 \mathrm{~min}$ of the in situ hydrogel gelation 

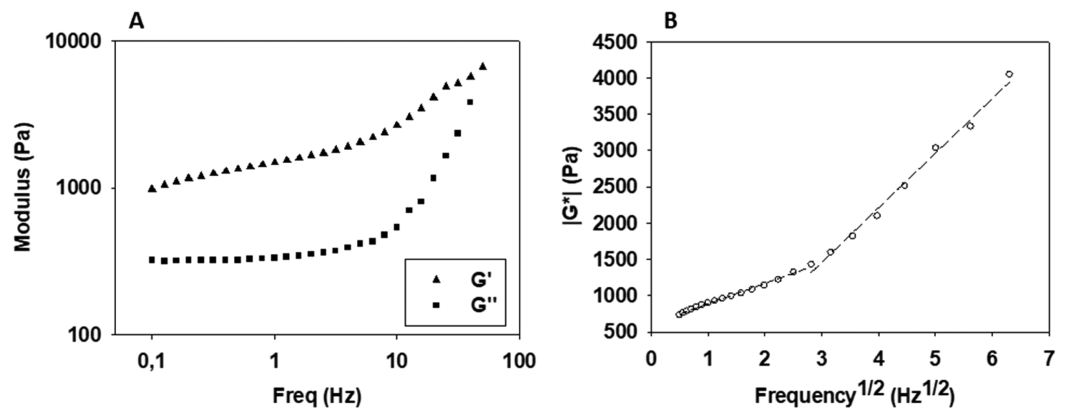

Figure 8. (A): Frequency dependence of the storage $\left(\mathrm{G}^{\prime}\right)$ and loss $\left(\mathrm{G}^{\prime \prime}\right)$ moduli for the $\mathrm{pA}(\mathrm{EIS})_{2}-\left(\mathrm{I}_{5} \mathrm{R}\right)_{6}$ hydrogels at $120 \mathrm{mg} / \mathrm{mL}$ with $24 \mathrm{~h}$ of preannealing. (B): Dependence of the magnitude of the complex modulus on $\mathrm{f}^{1 / 2}$ for the concentration of $120 \mathrm{mg} / \mathrm{mL}$. The dashed lines correspond to the least-squares linear regressions of each linear region. In every case, $R^{2}$ is better than 0.990 . Each curve corresponds to the average of three different samples measured.
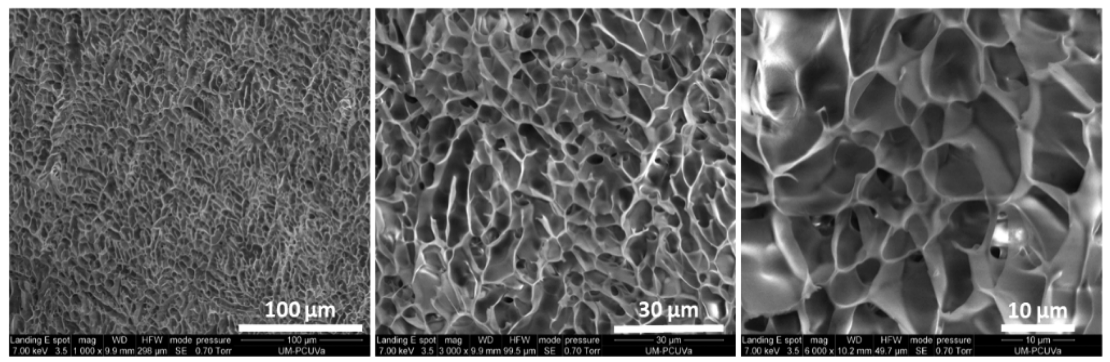

Figure 9. Representative SEM pictures for $\mathrm{pA}(\mathrm{EIS})_{2}-\left(\mathrm{I}_{5} \mathrm{R}\right)_{6}$ hydrogel at $120 \mathrm{mg} / \mathrm{mL}$ at different magnifications.

was finished, oscillatory rheological measurements were done, with special attention paid to the concentration of $120 \mathrm{mg} / \mathrm{mL}$ preannealed for $24 \mathrm{~h}$. First, a sweep in the amplitude of the test signal was carried out in a strain sweep test, which provided the linear range where the rheological characterization should take place. According to Figure S7 (SI), a wide linear range was obtained. As a trade-off between linearity and noise, a strain of $1 \%$ was chosen for every subsequent rheological measurement. Moreover, this figure also includes the results for the concentrations of 100,150 , and $180 \mathrm{mg} / \mathrm{mL}$, showing a clear trend: the higher the concentration, the higher the complex modulus.

Dynamic frequency sweep measurements were performed in the frequency range of 0.1 and $50 \mathrm{~Hz}$. The evolution of the storage modulus $\left(G^{\prime}\right)$ and the loss modulus $\left(G^{\prime \prime}\right)$ as a function of the frequency are represented in Figure 8A. Whereas a dependence of $G^{\prime}$ on frequency is observed, no significant dependence for $G^{\prime \prime}$ is found up to $10 \mathrm{~Hz}$. It should be pointed out that the value of $G^{\prime}$ is significantly higher than $G^{\prime \prime}$, which is calculated by the loss factor $\tan \delta \equiv \mathrm{G}^{\prime \prime} / \mathrm{G}^{\prime}$ (data not shown). Specifically, $\delta$ is around $12-13^{\circ}$ for the frequency of 1 $\mathrm{Hz}$, indicating a viscoelastic hydrogel behavior.

In order to obtain some information about the physical mechanisms that determine the frequency dependence of $\left|\mathrm{G}^{*}\right|$, the dependence of $\left|\mathrm{G}^{*}\right|$ on $\mathrm{f}^{1 / 2}$ for the hydrogel of $120 \mathrm{mg} / \mathrm{mL}$ is drawn in Figure 8B. A linear dependence based on two different slopes was found in the frequency range considered.

Scanning Electron Microscopy. pA(EIS $)_{2}-\left(\mathrm{I}_{5} \mathrm{R}\right)_{6}$ hydrogel at $120 \mathrm{mg} / \mathrm{mL}$ shows a pore size of $10.23 \pm 2.87 \mu \mathrm{m}$ and wall thickness of $0.71 \pm 0.12 \mu \mathrm{m}$ (Figure 9). $\mathrm{pA}(\mathrm{EIS})_{2}-\left(\mathrm{I}_{5} \mathrm{R}\right)_{6}$ hydrogels at 150 and $175 \mathrm{mg} / \mathrm{mL}$ show, respectively, a pore size of $6.97 \pm 2.30 \mu \mathrm{m}$ and $5.22 \pm 1.87 \mu \mathrm{m}$; and wall thickness of $1.85 \pm 1.40 \mu \mathrm{m}$ and $2.85 \pm 1.11 \mu \mathrm{m}$ (SI Figure S8). The $\mathrm{pA}(\mathrm{EIS})_{2}-\left(\mathrm{I}_{5} \mathrm{R}\right)_{6}$ hydrogels at all of the concentrations showed a $3 \mathrm{D}$ porous environment with an interconnected structure.
Cell Viability Assay. The chondrocytes (20 million cells/ $\mathrm{ml}$ ) were mixed with the hydrogel as described in Material and Methods. The mixture was further stained with DAPI (nuclear counterstain) according to the standard protocol. As shown in Figure S9 (SI), the cells were uniformly distributed. A metabolic activity assay was performed for the in vitro study at time 0,2 , and 4 weeks of culture. The cell viability analysis revealed an increase of metabolic activity, especially within the first 2 weeks, most likely due to the increase in number of cells; moreover, the viability of the cells remained high throughout the 4 weeks of culture, proving a suitable concentration of $\mathrm{pA}(\mathrm{EIS})_{2}-\left(\mathrm{I}_{5} \mathrm{R}\right)_{6}$ hydrogel (Figure 10).

\section{Cell Viability Analysis}

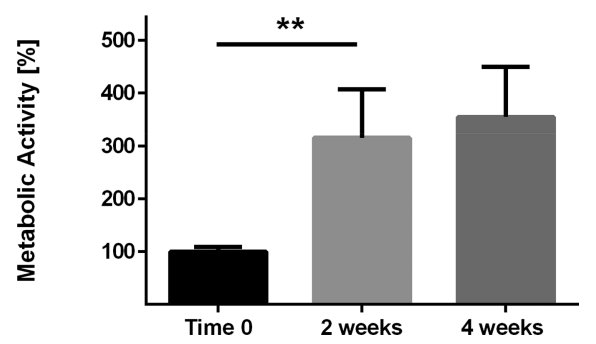

Figure 10. Cell viability test of $\mathrm{pA}(\mathrm{EIS})_{2}-\left(\mathrm{I}_{5} \mathrm{R}\right)_{6}$ with $24 \mathrm{~h}$ of preannealing at $120 \mathrm{mg} / \mathrm{mL} 3 \mathrm{D}$ gel embedded with pig chondrocytes $(20$ million $/ \mathrm{ml})$ at different time points $(* * P<0.01)$.

Biochemical Analysis. In order to quantify the GAG and the DNA content of the hydrogel embedded with chondrocytes for the in vitro and ex vivo study at day 0 and 28 , a biochemical analysis was performed. In both studies, an increase in DNA content was recorded with more significance in the ex vivo study (Figure 11). Moreover, at day 28, the DNA 
DNA quantification (in vitro study)

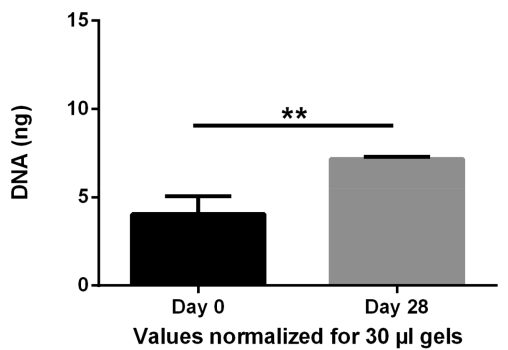

GAG quantification (in vitro study)

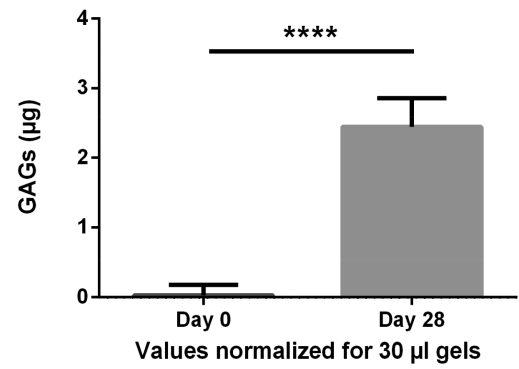

DNA quantification (ex vivo study)

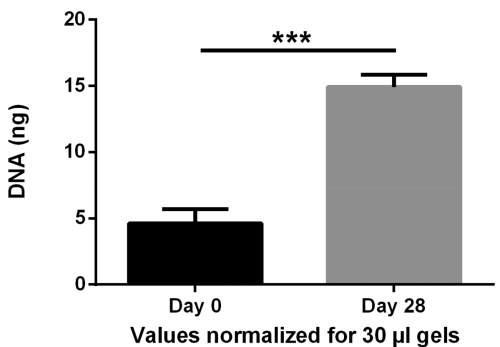

GAG quantification (ex vivo study)

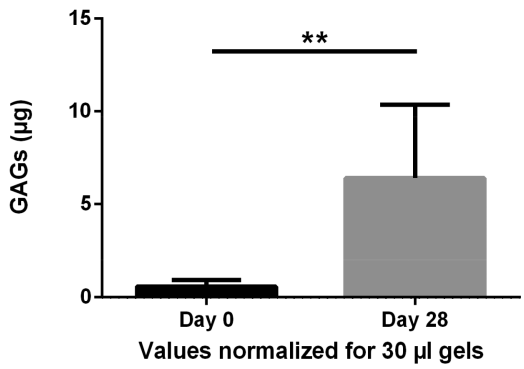

Figure 11. DNA and GAG content of the hydrogels embedded with chondrocytes for the in vitro and ex vivo study at day 0 and 28 . All the values have been normalized for $30 \mu \mathrm{L}$ volume of hydrogel $(* P<0.05$; **P $<0.01 ; * * P<0.001$; ****P<0.0001).
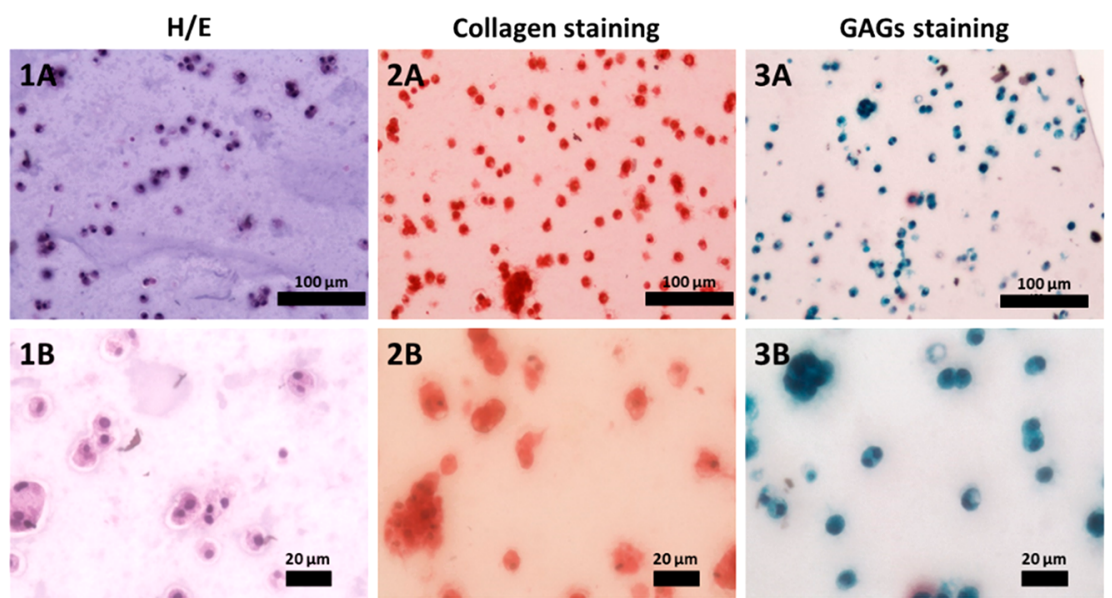

Figure 12. Histology of in vitro study with different staining and pictures collected at different magnifications (A,B): 1: H/E; 2: Collagen staining; 3: GAG staining.

content of the ex vivo study was higher compare to the in vitro study with a significant difference $(P<0.001)$.

The GAG content at day 0 has revealed the complete absence of polysaccharides, whereas at day 28 , we recorded a large presence of glycosaminoglycan in both studies (Figure 11 ). Comparing the GAG content at day 28 , the content was significantly higher in the ex vivo study than the content in the in vitro study $(P<0.05)$ (Figure 11$)$. Biochemical analysis of the hydrogel itself was performed for the in vitro and ex vivo study at days 0 and 28. As represented in Figure S10 (SI), in both studies the values remained approximately zero, meaning the absence of contribution in GAG and DNA content from the surrounding tissue (in the case of ex vivo study).

Histological Analysis. Histological analyses were performed for the hydrogels embedded with chondrocytes at day 28 for the in vitro (Figure 12) and ex vivo study (Figure 13).
For general histomorphological evaluation, the sections were stained with $\mathrm{H} / \mathrm{E}$; moreover, in order to evaluate the general collagen and GAG content produced by chondrocytes, the sections of hydrogels were stained with Picro-Sirius Red Stain and Safranin-O/Fast Green, respectively. For both studies, the $\mathrm{H} / \mathrm{E}$ staining reveled a very homogeneous distribution of chondrocytes embedded in the hydrogel. The Picro-Sirius Red Stain and Safranin-O/Fast Green demonstrated how the cells started to produce and secrete collagen and GAG and thus began forming their own ECM (see Figure 12B,C for the in vitro study and in Figure 13B,C for the ex vivo study).

Ex Vivo Study. Immunohistochemistry (IHC). The sections of the samples from in vitro study and ex vivo study at day 28 were immunostained with primary antibody anticollagen type I and anticollagen type II, in order identify the types of collagen stained by the general Picro-Sirius. The 


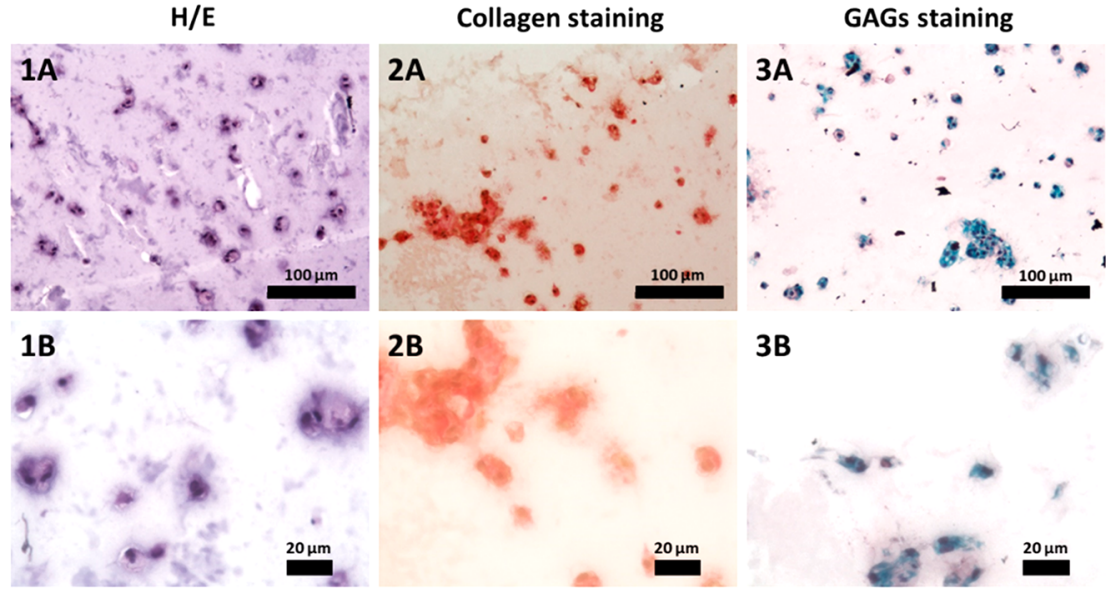

Figure 13. Histology of the ex vivo study with different staining and pictures collected at different magnifications $(\mathrm{A}, \mathrm{B}): 1: \mathrm{H} / \mathrm{E} ; 2$ : Collagen staining; 3: GAG staining.
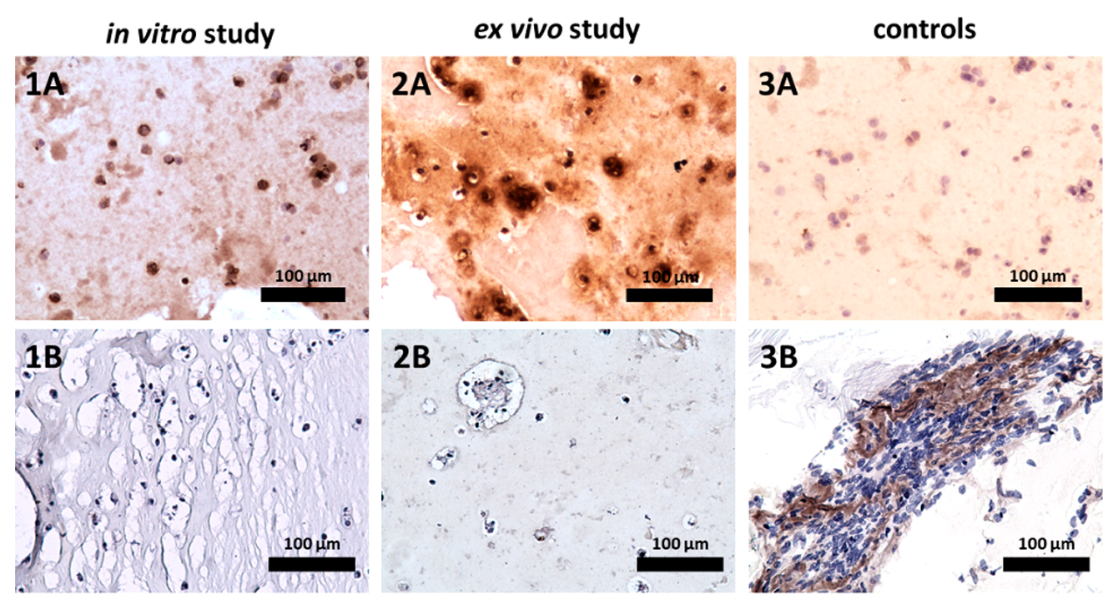

Figure 14. Immunohistochemistry of the in vitro and ex vivo study with $\mathrm{Ab}$ anticollagen type II and hematoxylin (respectively $1 \mathrm{~A}$ and $2 \mathrm{~A}$ ). Immunohistochemistry of the in vitro study and of the ex vivo study with $\mathrm{Ab}$ anticollagen type $\mathrm{I}$ and hematoxylin (respectively, $1 \mathrm{~B}$ and $2 \mathrm{~B}$ ). $3 \mathrm{~A}$ : Ctrl-: absence of Ab anti collagen type II; 3B: Ctrl+: IHC with Ab anti collagen type I and hematoxylin of hydrogel embedded with HFF1 cultured 21 days.

immunohistochemistry revealed the absence of collagen type I produced by chondrocytes in both studies (Figure 14B). The positive control for collagen type I was obtained embedding the hydrogel with HFF1 (Human foreskin fibroblasts 1). It is well-known that HFF1 are responsible for the production of collagen type I, which is a sign of fibro-cartilage formation. ${ }^{52}$ Diversely, in both studies, the IHC showed a clear signal for the antibody against collagen type II (hyaline cartilage), which is a sign of adequate cartilage regeneration (Figure 14A).

\section{DISCUSSION}

Tissue engineering for cartilage repair lacks biomaterials that have adequate mechanical properties capable of rapidly forming a gel that can be delivered into the area of interest via sample injection. Considering the unique properties of ELRs and silk, we have focused our attention on SELR obtained by recombinant techniques. The composition of this SELR is based on synthesized block corecombinamers, which have silk motifs, elastin motifs, and bioactive sequence (RGD). This SELR sequence contains the optimal content of silk motifs for adequate thermosensitive properties and for the expression in bacteria. ${ }^{28}$ Moreover, a repetition of six RGD sequences was included in order to have a good cellular adhesion response. ${ }^{53}$ The elastin motifs were designed to comprise a hydrophobic and hydrophilic block. The copolymer structures have been reported to form elastomeric hydrogels, in which the hydrophilic blocks provide conformational elastic properties and the hydrophobic blocks form cross-links by hydrophobic aggregation. ${ }^{30,31}$ Thus, SELR hydrogels are formed by the physical interactions from elastin motifs and silk motifs. In the first part of this study, we set up and optimized a preannealing treatment based on the evolution of silk motifs into $\beta$-sheet structures, in order to fulfill the required mechanical properties of hydrogels for cartilage repair. We finally obtained the proposed $\mathrm{pA}(\mathrm{EIS})_{2}-\left(\mathrm{I}_{5} \mathrm{R}\right)_{6}$. Afterward, we have carried out the characterization of our material with the combination of several experimental techniques (CD, TEM, SEM, and rheology), providing a deeper insight into the material features.

The CD spectra recorded at all temperatures indicates a predominantly disordered structure, where a proportional trend toward a more ordered structure can be appreciated for increasing preannealing times. This trend is based on the increase of the magnitude of the signal at $210 \mathrm{~nm}$ and at 197 $\mathrm{nm}$, associated with the presence of $\beta$-turns and $\beta$-sheet structures, respectively. Thus, $\mathrm{CD}$ has shown that the 

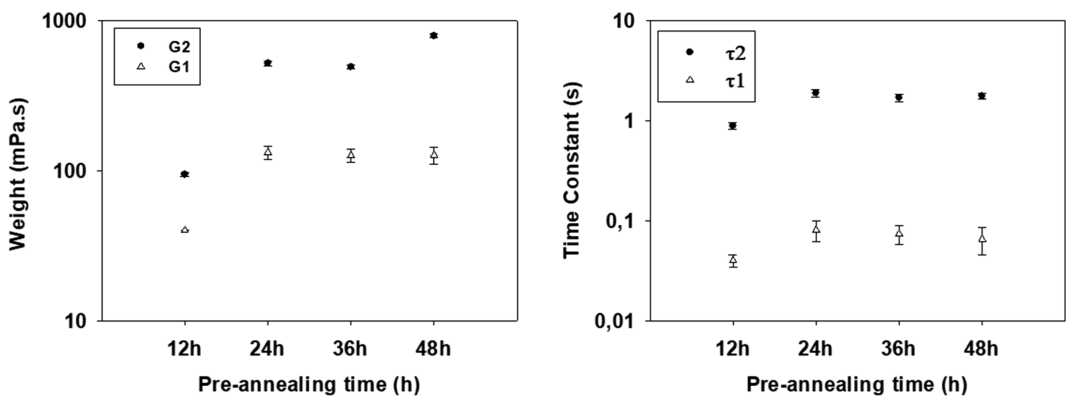

Figure 15. Fitted parameters according to eq 1 obtained from the numerical fitting of the experimental curves of Figure 4. A: G1 and G2; B: $\tau 1$ and $\tau 2$.

preannealing treatment speeds up the arrangement of silk motifs into $\beta$-sheet conformation.

It has already been investigated that a closely related ELR containing silk motifs is able to self-assemble into nanofibers through an evolution which is not immediate. ${ }^{26}$ The nanostructure formation of the $\mathrm{pA}(\mathrm{EIS})_{2}-\left(\mathrm{I}_{5} \mathrm{R}\right)_{6}$, checked by TEM (Figure 4), shows how these gels are able to form a dense network of fibers immediately after injection. This is due to the phenomenon of thermal memory, by which the supramolecular rearrangement of the silk motifs into $\beta$-sheets has been enhanced by the preannealing treatment (and conserved by the freeze-drying step). The density of the network of fibers for the $12 \mathrm{~h}$ preannealing time appears lower than for the group of 24, 36, and $48 \mathrm{~h}$.

The TEM results corroborate the CD analysis, where a similar trend has been observed.

The visualization of sol-gel behavior (Figure 5) has shown that the rearrangement of silk motifs into $\beta$-sheet conformation has a direct influence on the gelation process, allowing the gel formation at a lower concentration. Thereby, the gelation process for all the $\mathrm{pA}(\mathrm{EIS})_{2}-\left(\mathrm{I}_{5} \mathrm{R}\right)_{6}$ processes was investigated by rheological characterization.

At the end of the measuring time $(30 \mathrm{~min})$, the corresponding complex modulus are $100 \mathrm{mg} / \mathrm{mL}$ : $512 \mathrm{~Pa}$; $120 \mathrm{mg} / \mathrm{mL}: 1537 \mathrm{~Pa} ; 150 \mathrm{mg} / \mathrm{mL}: 2040 \mathrm{~Pa} ; 180 \mathrm{mg} / \mathrm{mL}$ : $3190 \mathrm{~Pa}$ (Figure 6B). This modulus increase with the concentration is possibly attributed to the increase of the hydrophobic interactions between the elastin motifs.

When the concentration is fixed $(120 \mathrm{mg} / \mathrm{mL})$, the dependence of moduli with the preannealing time shows a lower stiffness for the preannealing time of $12 \mathrm{~h}$, compared with longer annealing times. At the end of the measuring time (30 min), a similar modulus (around $1 \mathrm{kPa}$ ) is observed for the annealing time of 24,36 , and $48 \mathrm{~h}$ (Figure 6A). Because in this case the percentage of elastin is constant, these moduli are related to the presence of $\beta$-sheets. Thus, a similar maturation of $\beta$-sheets is suggested for annealing times from 24 to $48 \mathrm{~h}$. This result agrees with the results obtained by using CD and TEM.

It has been reported that the concentration of $120 \mathrm{mg} / \mathrm{mL}$ represented a cutoff to obtain a significant effects of the preannealing treatment. Moreover, Figure $6 \mathrm{~B}$ shows how for the $\mathrm{pA}(\mathrm{EIS})_{2}-\left(\mathrm{I}_{5} \mathrm{R}\right)_{6}$ at $100 \mathrm{mg} / \mathrm{mL}$, there are no changes for 24 and $48 \mathrm{~h}$ annealing times.

The higher the concentration of $\mathrm{pA}(\mathrm{EIS})_{2}-\left(\mathrm{I}_{5} \mathrm{R}\right)_{6}$ in the hydrogel, the more difficult it is to dissolve the material but also to mix in cells, while still achieving a homogeneous cell distribution, because of the high viscosity. It can also be expected that more gel is lost during handling by attachment to syringes or pipet tips. Thus, solution viscosity is a significant parameter during the injection process.

The preannealing treatment affects the viscosity. It has been previously reported that the annealing time impacts the formation and maturation of the $\beta$-sheets existing in silkbased ELRs. ${ }^{26}$ Thus, this increased viscosity may be related to the different $\beta$-sheet structures induced by the annealing process. The dependence of viscosity on the shear rate (Figure 7) suggests modeling according to the equation

$$
\eta(\text { sh-rate })=\eta \infty+\sum_{i=1}^{2} \mathrm{Gi} \cdot \exp ^{-\tau \mathrm{i} \cdot(\text { sh-rate })}
$$

based on a series of two decreasing exponential functions (Maxwell dependence), where $\tau \mathrm{i}$ are the relaxation time constants, and $\mathrm{Gi}$ are the weight of the $\tau \mathrm{i}$-type relaxation to the overall relaxation process that is mainly dominated by each time constant within the corresponding shear rate range. Finally, $\eta \infty$ corresponds to the viscosity at an enormous (infinite) shear rate.

The impact of the different annealing times on the viscosity corroborates the behavior recorded in the $\mathrm{CD}$ analysis at the same temperature $\left(4^{\circ} \mathrm{C}\right)$ (Figure $\left.3 \mathrm{~A}\right)$. Rheological flow measurements are in agreement with supramolecular analysis like CD and TEM. Moreover, considering that the temperature of the analysis for CD and rheological flow measurements is lower than the $T_{\mathrm{t}}$ of the SELRs, we can assume that the $\beta$-sheet structures formed by the preannealing treatment are conserved even after the freeze-drying step.

The experimental data of Figure 7 has been numerically fitted to eq 1 , and all the parameters have been obtained (Figure 15A,B). As can be seen, a threshold is again observed for the preannealing of $12 \mathrm{~h}$ both for the weights and the time constants of relaxation. For a fixed relaxation process, no noticeable changes are found for samples annealed for 24,36 , and $48 \mathrm{~h}$, although for $\mathrm{G} 1$ the weight for the $48 \mathrm{~h}$ annealed sample is slightly higher. The relaxation process 1 shows a very short relaxation time (lower than $0.1 \mathrm{~s}$ ), while the time constant of the second relaxation process is higher than $1 \mathrm{~s}$.

Thus, the annealing time of $24 \mathrm{~h}$ has been selected in our work as a trade-off between enough maturation of the $\beta$-sheet structures and to make the injection process easier.

The rheological properties of the $\mathrm{pA}(\mathrm{EIS})_{2}-\left(\mathrm{I}_{5} \mathrm{R}\right)_{6}$ hydrogels with $24 \mathrm{~h}$ of preannealing at $120 \mathrm{mg} / \mathrm{mL}$ are in agreement with the soft tissue engineering properties of hydrogel for biomedical application. ${ }^{54,55}$ Dynamic frequency sweep measurements show at the frequency of $1 \mathrm{~Hz}^{\prime} \mathrm{G}^{\prime}: 1489 \mathrm{~Pa}$ and a $\mathrm{G}^{\prime \prime}$ : $334 \mathrm{~Pa}$. As can be seen (where $\mathrm{G}^{\prime} \gg \mathrm{G}^{\prime \prime}$ ), the values of delta (specifically, $\delta$ is around $12-13^{\circ}$ for the frequency of 1 
$\mathrm{Hz}$ ) for the $\mathrm{pA}(\mathrm{EIS})_{2}-\left(\mathrm{I}_{5} \mathrm{R}\right)_{6}$ hydrogels at $120 \mathrm{mg} / \mathrm{mL}$ are in agreement with the viscoelastic behavior that has also been demonstrated in cartilage. ${ }^{56}$

As for the physical mechanisms taking part in the rheological behavior of the hydrogel, the linear dependence of the complex modulus with $\mathrm{f}^{1 / 2}$ (Figure $8 \mathrm{~B}$ ) indicates that a poroelastic mechanism dominates the viscoelastic behavior in this frequency range. In the poroelastic mechanism, viscous drag of interstitial fluid (water) through the porous recombinamer network and fluid-solid frictional interactions due to fluid pressurization are predominant. ${ }^{57,58}$

The slope is related to the hydrogel permeability that is a macroscopic measure of the ease with which a fluid can flow through the hydrogel matrix. In our case, two slopes are observed, whose values were numerically fitted: $282 \pm 6 \mathrm{~Pa} /$ $\mathrm{Hz}^{1 / 2}$ for $\mathrm{f}^{1 / 2}<2.5 \mathrm{~Hz}^{1 / 2}$, and $753 \pm 28 \mathrm{~Pa} / \mathrm{Hz}^{1 / 2}$ for $\mathrm{f}^{1 / 2}>2.5$ $\mathrm{Hz}^{1 / 2}$. Thus, the slope increases when the frequency exceeds $6.25 \mathrm{~Hz}$. A slope increase was associated with a decrease in hydrogel permeability. ${ }^{54,59}$ A similar behavior was reported for elastin-like catalyst free click gels ${ }^{54}$ and hybrid elastin-like recombinamer-fibrin gels. ${ }^{60}$ However, in both cases, a single slope was obtained throughout the frequency range analyzed.

The preannealing treatment does have an effect on the gelation process. In fact, the observed increase in the storage modulus of $\mathrm{pA}(\mathrm{EIS})_{2}-\left(\mathrm{I}_{5} \mathrm{R}\right)_{6}$ hydrogels (Figure $6 \mathrm{~A}$ ) indicates the contribution of the preannealing treatment on the gelation process by the increase of the cross-linking network. Moreover, the preannealing treatment has an impact on the concentration of the hydrogel, allowing the formation of the hydrogel at a lower concentration than that observed by Fonseca et al. ${ }^{27}$

Fernandez-Colino et al. reported how the elastin contribution leads to the rapid and early formation of a hydrogel, whereas the silk domains can increase the modulus of the hydrogel over time. ${ }^{26}$ The same behavior has been recorded with the $\mathrm{pA}(\mathrm{EIS})_{2}-\left(\mathrm{I}_{5} \mathrm{R}\right)_{6}$ hydrogels, with regards to the preannealing treatment that accelerates the $\beta$-sheet formation. $\mathrm{CD}$ and TEM confirms this phenomenon of thermal memory based on the growth-boosting of the $\beta$-sheet formation, which exerts an indirect influence on temperature trigger gelation.

Therefore, taking into account the two slopes observed both in the evolution of the complex modulus with $\mathrm{f} 1 / 2$ and in the viscosity dependence on the shear rate, we tentatively suggest that these two slopes are related to the two interactions existing in our silk-based ELR: the hydrophobic interaction associated with elastin and the $\beta$-sheet interaction due to the silk-block. Both of them contribute to the cross-linking network of the physical hydrogel. In the oscillatory measurements, the higher slope, corresponding to a higher hindrance of the fluid flow through the hydrogel structure, might be associated with the $\beta$-sheet structures, which are stiffer and more rigid than the elastin interaction.

As for flow measurements, because more rigid blocks take more time to respond, the first process (characterized by G1 and $\tau 1$ ) might be related to the $\beta$-sheet structures. Following this idea, Figure 11 shows that both the $\beta$-sheets and the hydrophobic elastin interactions are affected by the preannealing time, although the former to a greater extent. Thus, it is suggested that both physical interactions are not independent but that the maturation of the $\beta$-sheet structures the spatial location of the hydrophobic blocks modifies, altering this interaction, as it has been recently reported by Fonseca et al. ${ }^{27}$

The morphology of the $\mathrm{pA}(\mathrm{EIS})_{2}-\left(\mathrm{I}_{5} \mathrm{R}\right)_{6}$ hydrogels at 120 , 150 , and $180 \mathrm{mg} / \mathrm{mL}$ was investigated by SEM (Figure 9 and
Figure S8). The fibrillary structure, obtained by the preannealing treatment, does not negatively influence the porosity of the hydrogel; in fact, $\mathrm{pA}(\mathrm{EIS})_{2}-\left(\mathrm{I}_{5} \mathrm{R}\right)_{6}$ hydrogels show a homogeneous porous environment with an interconnected structure. Porosity plays a critical role in the outcome of a tissue-engineered scaffold; the cells seeded in there rely heavily on the void spaces within the construct for cellular in-growth, exchange of nutrients, and removal of waste products. ${ }^{61}$ In addition, the extent of ECM secretion also increases by increasing pore size. ${ }^{62}$ Moreover, the chondrocytes are the exclusive cells in articular cartilage, with a size of $10-13 \mu \mathrm{m}$ diameters and are involved in the synthesis of the cellular matrix constituents. ${ }^{63}$ Considering the pore size of the $\mathrm{pA}(\mathrm{EIS})_{2}-\left(\mathrm{I}_{5} \mathrm{R}\right)_{6}$ hydrogels at $120 \mathrm{mg} / \mathrm{mL}: 10.23 \pm 2.87 \mu \mathrm{m}$, $\mathrm{pA}(\mathrm{EIS})_{2}-\left(\mathrm{I}_{5} \mathrm{R}\right)_{6}$ hydrogel at $120 \mathrm{mg} / \mathrm{mL}$ presents a suitable pore size to create a $3 \mathrm{D}$ matrix embedded with chondrocytes.

In summary, the first part of the study intended to characterize the material proposed and to understand the physical contribution of the silk motifs in relation to the elastin motifs for the cross-linkage of the hydrogel. We have paid particular attention to the characterization of the $\mathrm{pA}(\mathrm{EIS})_{2}$ $\left(\mathrm{I}_{5} \mathrm{R}\right)_{6}$ hydrogels with different annealing times $(12,24,36$, and $48 \mathrm{~h})$ and different concentrations (100,120,150,180 mg/ $\mathrm{mL})$. From the combination of the experimental results obtained by various techniques, the concentration of 120 $\mathrm{mg} / \mathrm{mL}$ preannealed for $24 \mathrm{~h}$ established a threshold for gelation, and these conditions were selected as the most suitable candidate as injectable hydrogel for cartilage repair. The second part of the study focused on the potential of the selected $\mathrm{pA}(\mathrm{EIS})_{2}-\left(\mathrm{I}_{5} \mathrm{R}\right)_{6}$ hydrogels with $24 \mathrm{~h}$ of preannealing at $120 \mathrm{mg} / \mathrm{mL}$, as a good candidate for cartilage repair.

A well-accepted tissue-engineering paradigm is that, the most successful scaffold for tissue repair is a biomaterial that mimics the functional properties of native tissue extra cellular matrix (ECM), facilitates encapsulation of reparative cells and is supportive of cell repair activities, including proliferation and de novo production of ECM. ${ }^{64}$ Although the biocompatibility of ELR-based hydrogels formed through physical cross-linking has been extensively studied, ${ }^{53}$ in this study we have performed for the first time a 4 week culturing metabolic activity assay of the $\mathrm{pA}(\mathrm{EIS})_{2}-\left(\mathrm{I}_{5} \mathrm{R}\right)_{6}$ hydrogel embedded with chondrocytes. The cell viability analysis has revealed that the selected concentration $(120 \mathrm{mg} / \mathrm{mL})$ supports cell viability and metabolic activity. In order to evaluate the regenerative abilities of our newly developed hydrogel-scaffold systems, a well established ex vivo model as a culture platform was used. ${ }^{37,65}$ The biggest advantage of using this ex vivo model is to test biomaterials in a native environment for relevant culture period, with the possibility to oversee the healing process monitoring the physiological and biochemical contents of the regenerated tissue.

In Figure 11, DNA and GAG content is shown. In both cases, the content is obtained for a given volume of hydrogel analyzed. ${ }^{66,67}$ The increase in DNA and GAG content recorded through biochemical analysis shows how the $\mathrm{pA}(\mathrm{EIS})_{2}-\left(\mathrm{I}_{5} \mathrm{R}\right)_{6}$ hydrogel is an appropriate scaffold for chondrocytes embedding involved in cartilage repair. Furthermore, comparing the biochemical contents of the in vitro study with the ex vivo study, the DNA quantification shows how the osteochondral culture platform facilitates a better proliferation of chondrocytes. The same trend was observed with respect to GAG content, where the glycosaminoglycan content of the ex vivo study was higher compared with the in 
vitro study. According to previous work, the GAG density observed in our study was still not in the same range of mature cartilage. ${ }^{68}$ This was expected, considering that 28 days is a short time to obtain a mature regenerated cartilage. Anyway, comparing our scaffold with other hydrogel systems for cartilage repair, the media GAG content normalized to DNA obtained for our system ( $427 \mu \mathrm{g}$ of GAG per $\mu \mathrm{g}$ of DNA) demonstrated a larger production of glycosaminoglycan. ${ }^{69}$

The biochemical analysis for GAGs and DNA confirms that the ex vivo osteochondral culture platform is a good and representative model to evaluate the healing progress in created cartilage defects.

Histological analysis confirms the biochemical results, showing a higher amount of GAGs stained by Safranin-O/ Fast Green in the ex vivo study. Moreover, the Picro-Sirius Red Stain staining revealed a larger production of collagen by the chondrocytes cultured in the ex vivo osteochondral culture platform. Finally, for both studies, the H/E staining demonstrated a very homogeneous distribution of chondrocytes embedded in the hydrogel, showing efficient mixing of the matrix with the cells achieved by the adequate concentration of the hydrogel. Some cells look like they underwent a mitosis step (Figure 12: 1A, 2A and Figure 13: $1 \mathrm{~A}, 2 \mathrm{~A})$, and these results are in accordance with the values obtained by biochemical analysis for the DNA content.

Immunohistochemistry for collagen type I and collagen type II revealed the absence of collagen type I (a sign of undesired fibro-cartilage formation) in both studies. Diversely, the IHC in both studies showed a clear signal for the antibody against collagen type II (hyaline cartilage); furthermore, the IHC revealed a better production and secretion of collagen type II in the ex vivo study compared with the in vitro study. The absence of collagen type I and the production of collagen type II, which gives tensile strength to cartilage, ${ }^{70}$ proves that $\mathrm{pA}(\mathrm{EIS})_{2}-\left(\mathrm{I}_{5} \mathrm{R}\right)_{6}$ hydrogel is an excellent candidate for osteochondral repair.

As it is widely reported in literature, agarose and PEG hydrogels are considered ones of the best alternatives for cartilage tissue engineering because of the good biological and mechanical properties. ${ }^{66,71,72}$ However, they do not provide specific biological functions, which could be obtained by the recombinant protein technique used in our study for a bioactive hydrogel. Moreover, after 28 days of culturing in the ex vivo platform, our hydrogel demonstrated a GAG production per $\mu \mathrm{g}$ of DNA around 10 times more than in the case of PEG or agarose based scaffolds. ${ }^{69}$

Finally, the analysis recorded for the ex vivo study with the osteochondral culture platform confirms the importance of a native environment for the production of hyaline cartilage by mature chondrocytes.

\section{CONCLUSIONS}

We developed and produced the preannealed Silk Elastin coRecombinamer $\left(\mathrm{pA}(\mathrm{EIS})_{2}-\left(\mathrm{I}_{5} \mathrm{R}\right)_{6}\right)$, which shows unique properties as a promising candidate for tissue engineering applications. We have focused on the need for biomaterials for cartilage repair, capable of being delivered into the area of interest, showing a rapid gelation and adequate mechanical properties when surrounded by synovial fluid. We have set up and optimized a preannealing treatment based on the evolution of silk motifs into $\beta$-sheet structures and on the phenomenon of thermal memory. In this study, we have carried out the physical characterization of our material in order to provide a deeper insight into the material features, analyzing the contribution of each component (silk and elastin) for the cross-linking formation. The $\mathrm{pA}(\mathrm{EIS})_{2}-\left(\mathrm{I}_{5} \mathrm{R}\right)_{6}$ has shown a fast gelation, improved mechanical properties, and the presence of a fibrillary structure directly after injection of the hydrogel. Moreover, culturing the hydrogel embedded with chondrocytes in the ex vivo culture platform for weeks has exhibited good biocompatibility and remarkable advantages; such as the de novo ECM formation, the absence of fibro-cartilage, and the production of hyaline cartilage. The addition of the silk allows making hydrogels with a lower concentration, leading to larger pores, which is most likely responsible for better cell spreading and proliferation. In conclusion, the $\mathrm{pA}(\mathrm{EIS})_{2}-\left(\mathrm{I}_{5} \mathrm{R}\right)_{6}$ has been shown to have new outstanding properties, which make the hydrogel a promising injectable scaffold in the field of cartilage regeneration.

\section{ASSOCIATED CONTENT}

\section{Supporting Information}

The Supporting Information is available free of charge on the ACS Publications website at DOI: 10.1021/acs.biomac.8b01211.

SDS-PAGE analysis, MALDI-TOF spectra, amino acid composition, FTIR spectra, DSC analysis, and H NMR spectra for the $\mathrm{pA}(\mathrm{EIS})_{2}-\left(\mathrm{I}_{5} \mathrm{R}\right)_{6}$; dependence of the viscosity for an identical recombinamer hydrogels lacking the silk blocks with different preannealing times; strain dependence of $\left|\mathrm{G}^{*}\right|$ for the $24 \mathrm{~h}$ preannealed $\mathrm{pA}(\mathrm{EIS}) 2-(\mathrm{I} 5 \mathrm{R}) 6$ hydrogels at different concentrations; SEM analysis for the $\mathrm{pA}(\mathrm{EIS})_{2}-\left(\mathrm{I}_{5} \mathrm{R}\right)_{6}$ hydrogels at different concentrations; fluorescent microscope image of the hydrogel embedded with chondrocytes after DAPI staining; and biochemical analysis of the hydrogel alone for the in vitro and ex vivo study (PDF)

\section{AUTHOR INFORMATION}

\section{Corresponding Author}

*E-mail: fcipriani@tpnbt.com.

ORCID $\odot$

Filippo Cipriani: 0000-0002-9738-1449

\section{Author Contributions}

The manuscript was written through contributions of all authors. All authors have given approval to the final version of the manuscript

Notes

The authors declare no competing financial interest.

\section{ACKNOWLEDGMENTS}

This project has received funding from the European Union's Horizon 2020 research and innovation programme under the Marie Sklodowska-Curie grant agreement No. 642687. The authors are grateful for the funding from the European Commission (NMP-2014-646075), the Spanish Government (PCIN-2015-010, MAT2015-68901-R, MAT2016-78903-R, MAT2016-79435-R), Junta de Castilla y León (VA015U16), and Centro en Red de Medicina Regenerativa y Terapia Celular de Castilla y León. 


\section{REFERENCES}

(1) Buckwalter, J. A.; Mankin, H. J. Articular cartilage: tissue design and chondrocyte-matrix interactions. Instr. Course Lect. 1998, 47, $477-486$.

(2) Amadio, P. C. Friction of the Gliding Surface: Implications for Tendon Surgery and Rehabilitation. Journal of hand therapy: official journal of the American Society of Hand Therapists 2005, 18 (2), 112119.

(3) Tuli, R.; Li, W.-J.; Tuan, R. S. Current state of cartilage tissue engineering. Arthritis Res. Ther 2003, 5 (5), 235.

(4) Huey, D. J.; Hu, J. C.; Athanasiou, K. A. Unlike Bone, Cartilage Regeneration Remains Elusive. Science 2012, 338 (6109), 917-921.

(5) Griffith, L. G.; Naughton, G. Tissue Engineering-Current Challenges and Expanding Opportunities. Science 2002, 295 (5557), 1009-1014.

(6) Daley, W. P.; Peters, S. B.; Larsen, M. Extracellular matrix dynamics in development and regenerative medicine. J. Cell Sci. 2008, 121 (3), 255-264.

(7) Maroudas, A.; Bullough, P.; Swanson, S. A.; Freeman, M. A. The permeability of articular cartilage. J. Bone Jt. Surg., Br. Vol. 1968, 50-B (1), 166-177.

(8) Kheir, E.; Shaw, D. Hyaline articular cartilage. Orthopaedics and Trauma 2009, 23 (6), 450-455.

(9) Sophia Fox, A. J.; Bedi, A.; Rodeo, S. A. The Basic Science of Articular Cartilage: Structure, Composition, and Function. Sports Health 2009, 1 (6), 461-468.

(10) Erkamp, R. Q.; Wiggins, P.; Skovoroda, A. R.; Emelianov, S. Y.; O'Donnell, M. Measuring the Elastic Modulus of Small Tissue Samples. Ultrasonic Imaging 1998, 20 (1), 17-28.

(11) Freeman, P. M.; Natarajan, R. N.; Kimura, J. H.; Andriacchi, T. P. Chondrocyte cells respond mechanically to compressive loads. J. Orthop. Res. 1994, 12 (3), 311-320.

(12) Mow, V. C.; Holmes, M. H.; Michael Lai, W. Fluid transport and mechanical properties of articular cartilage: A review. J. Biomech. 1984, 17 (5), 377-394.

(13) Marijnissen, W. J. C. M.; van Osch, G. J. V. M.; Aigner, J.; van der Veen, S. W.; Hollander, A. P.; Verwoerd-Verhoef, H. L.; Verhaar, J. A. N. Alginate as a chondrocyte-delivery substance in combination with a non-woven scaffold for cartilage tissue engineering. Biomaterials 2002, 23 (6), 1511-1517.

(14) Muir, H. The chondrocyte, architect of cartilage-biomechanics, structure, function and molecular-biology of cartilage matrix macromolecules. BioEssays 1995, 17, 1039-1048.

(15) Wall, A.; Board, T. Mesenchymal Cell-Based Repair of Large Full Thickness Defects of Articular Cartilage. In Classic Papers in Orthopaedics; Banaszkiewicz, P. A., Kader, D. F., Eds.; Springer London: London, 2014; pp 441-443.

(16) Dewan, A. K.; Gibson, M. A.; Elisseeff, J. H.; Trice, M. E. Evolution of Autologous Chondrocyte Repair and Comparison to Other Cartilage Repair Techniques. BioMed Res. Int. 2014, 2014, Article ID 272481.

(17) Caldwell, K. L.; Wang, J. Cell-based articular cartilage repair: the link between development and regeneration. Osteoarthritis Cartilage 2015, 23, 351-62.

(18) Nagaya, H.; Ymagata, T.; Ymagata, S.; Iyoda, K.; Ito, H.; Hasegawa, Y.; Iwata, H. Examination of synovial fluid and serum hyaluronidase activity as a joint marker in rheumatoid arthritis and osteoarthritis patients (by zymography). Ann. Rheum. Dis. 1999, 58, $186-188$.

(19) Shen, Y.; Fu, Y.; Wang, J.; Li, G.; Zhang, X.; Xu, Y. Z.; Lin, Y. Biomaterial and mesenchymal stem cell for articular cartilage reconstruction. Curr. Stem Cell Res. Ther. 2014, 9, 254-267.

(20) Armiento, A. R.; Stoddart, M. J.; Alini, M.; Eglin, D. Biomaterials for articular cartilage tissue engineering: Learning from biology. Acta Biomater. 2018, 65, 1-20.

(21) Girotti, A.; Orbanic, D.; Ibáñez-Fonseca, A.; Gonzalez-Obeso, C.; Rodríguez-Cabello, J. C. Recombinant Technology in the Development of Materials and Systems for Soft-Tissue Repair. Adv. Healthcare Mater. 2015, 4 (16), 2423-2455.
(22) Urry, D. W. Molecular Machines: How Motion and Other Functions of Living Organisms Can Result from Reversible Chemical Changes. Angew. Chem., Int. Ed. Engl. 1993, 32 (6), 819-841.

(23) Ribeiro, A.; Arias, F. J.; Reguera, J.; Alonso, M.; RodríguezCabello, J. C. Influence of the Amino-Acid Sequence on the Inverse Temperature Transition of Elastin-Like Polymers. Biophys. J. 2009, 97 (1), 312-320.

(24) McDaniel, J. R.; Radford, D. C.; Chilkoti, A. A Unified Model for De Novo Design of Elastin-like Polypeptides with Tunable Inverse Transition Temperatures. Biomacromolecules 2013, 14 (8), 2866-72.

(25) Martín, L.; Alonso, M.; Girotti, A.; Arias, F. J.; RodríguezCabello, J. C. Synthesis and Characterization of Macroporous Thermosensitive Hydrogels from Recombinant Elastin-Like Polymers. Biomacromolecules 2009, 10 (11), 3015-3022.

(26) Fernández-Colino, A.; Arias, F. J.; Alonso, M.; RodríguezCabello, J. C. Self-Organized ECM-Mimetic Model Based on an Amphiphilic Multiblock Silk-Elastin-Like Corecombinamer with a Concomitant Dual Physical Gelation Process. Biomacromolecules 2014, 15 (10), 3781-3793.

(27) Ibáñez-Fonseca, A.; Alonso, M.; Arias, F. J.; Rodríguez-Cabello, J. C. Förster Resonance Energy Transfer-Paired Hydrogel Forming Silk-Elastin-Like Recombinamers by Recombinant Conjugation of Fluorescent Proteins. Bioconjugate Chem. 2017, 28 (3), 828-835.

(28) Cappello, J.; Crissman, J.; Dorman, M.; Mikolajczak, M.; Textor, G.; Marquet, M.; Ferrari, F. Genetic engineering of structural protein polymers. Biotechnol. Prog. 1990, 6 (3), 198-202.

(29) Ruoslahti, E.; Pierschbacher, M. D. Arg-Gly-Asp: A versatile cell recognition signal. Cell 1986, 44 (4), 517-518.

(30) Sallach, R. E.; Cui, W.; Wen, J.; Martinez, A.; Conticello, V. P.; Chaikof, E. L. Elastin-mimetic protein polymers capable of physical and chemical crosslinking. Biomaterials 2009, 30 (3), 409-22.

(31) Martin, L.; Arias, F. J.; Alonso, M.; Garcia-Arevalo, C.; Rodriguez-Cabello, J. C. Rapid micropatterning by temperaturetriggered reversible gelation of a recombinant smart elastin-like tetrablock-copolymer. Soft Matter 2010, 6 (6), 1121-1124.

(32) Friedl, P. Prespecification and plasticity: shifting mechanisms of cell migration. Curr. Opin. Cell Biol. 2004, 16 (1), 14-23.

(33) Kuchler-Bopp, S.; Bécavin, T.; Kökten, T.; Fioretti, F.; Deveaux, E.; Benkirane-Jessel, N.; Keller, L. Nanostructured hybrid materials for bone-tooth unit regeneration. Open J. Regener. Med. 2013, 02 (03), 47-52.

(34) Bernhard, J. C.; Vunjak-Novakovic, G. Should we use cells, biomaterials, or tissue engineering for cartilage regeneration? Stem Cell Res. Ther. 2016, 7 (1), 56.

(35) Rodríguez Cabello, J. C.; De Torre, I. G.; Cipriani, F.; Poocza, L. 12 - Elastin-like materials for tissue regeneration and repair. In Peptides and Proteins as Biomaterials for Tissue Regeneration and Repair; Barbosa, M. A., Martins, M. C. L., Eds.; Woodhead Publishing, 2018; pp 309-327.

(36) Sallach, R. E.; Cui, W.; Balderrama, F.; Martinez, A. W.; Wen, J.; Haller, C. A.; Taylor, J. V.; Wright, E. R.; Long, R. C.; Chaikof, E. L. Long-term biostability of self-assembling protein polymers in the absence of covalent crosslinking. Biomaterials 2010, 31 (4), 779-791.

(37) Schwab, A.; Meeuwsen, A.; Ehlicke, F.; Hansmann, J.; Mulder, L.; Smits, A.; Walles, H.; Kock, L. Ex vivo culture platform for assessment of cartilage repair treatment strategies; Clinical Orthopaedics and Related Research, 2016; Vol. 34, pp 17-26.

(38) Plunkett, N.; O'Brien, F. IV.3. Bioreactors in tissue engineering. Stud Health Technol Inform. 2010, 19, 55-69.

(39) Cook, J. L.; Hung, C. T.; Kuroki, K.; Stoker, A. M.; Cook, C. R.; Pfeiffer, F. M.; Sherman, S. L.; Stannard, J. P. Animal models of cartilage repair. Bone and Joint Research 2014, 3 (4), 89-94.

(40) Hurtig, M. B.; Buschmann, M. D.; Fortier, L. A.; Hoemann, C. D.; Hunziker, E. B.; Jurvelin, J. S.; Mainil-Varlet, P.; McIlwraith, C. W.; Sah, R. L.; Whiteside, R. A. Preclinical Studies for Cartilage Repair. Cartilage 2011, 2 (2), 137-152.

(41) Martín, L.; Arias, F. J.; Alonso, M.; García-Arevalo, C.; Rodríguez-Cabello, J. C. Rapid micropatterning by temperature- 
triggered reversible gelation of a recombinant smart elastin-like tetrablock-copolymer. Soft Matter 2010, 6 (6), 1121-1124.

(42) Reguera, J.; Fahmi, A.; Moriarty, P.; Girotti, A.; RodríguezCabello, J. C. Nanopore Formation by Self-Assembly of the Model Genetically Engineered Elastin-like Polymer [(VPGVG)2(VPGEG)(VPGVG)2]15. J. Am. Chem. Soc. 2004, 126 (41), 13212-13213.

(43) Girotti, A.; Reguera, J.; Arias, F. J.; Alonso, M.; Testera, A. M.; Rodríguez-Cabello, J. C. Influence of the Molecular Weight on the Inverse Temperature Transition of a Model Genetically Engineered Elastin-like pH-Responsive Polymer. Macromolecules 2004, 37 (9), 3396-3400.

(44) García-Arévalo, C.; Bermejo-Martín, J. F.; Rico, L.; Iglesias, V.; Martín, L.; Rodríguez-Cabello, J. C.; Arias, F. J. Immunomodulatory Nanoparticles from Elastin-Like Recombinamers: Single-Molecules for Tuberculosis Vaccine Development. Mol. Pharmaceutics 2013, 10 (2), 586-597.

(45) Rodríguez-Cabello, J. C.; Girotti, A.; Ribeiro, A.; Arias, F. J. Synthesis of Genetically Engineered Protein Polymers (Recombinamers) as an Example of Advanced Self-Assembled Smart Materials. In Nanotechnology in Regenerative Medicine: Methods and Protocols; Navarro, M., Planell, J. A., Eds.; Humana Press: Totowa, NJ, 2012; pp $17-38$.

(46) Costa, R. R.; Custódio, C. A.; Arias, F. J.; Rodríguez-Cabello, J. C.; Mano, J. F. Layer-by-Layer Assembly of Chitosan and Recombinant Biopolymers into Biomimetic Coatings with Multiple Stimuli-Responsive Properties. Small 2011, 7 (18), 2640-2649.

(47) Urry, D. W.; Shaw, R. G.; Prasad, K. U. Polypentapeptide of elastin: Temperature dependence of ellipticity and correlation with elastomeric force. Biochem. Biophys. Res. Commun. 1985, 130 (1), 5057.

(48) Farndale, R. W.; Sayers, C. A.; Barrett, A. J. A Direct Spectrophotometric Microassay for Sulfated Glycosaminoglycans in Cartilage Cultures. Connect. Tissue Res. 1982, 9 (4), 247-248.

(49) Urry, D. W.; Long, M. M.; Ohnishi, T.; Jacobs, M. Circular dichroism and absorption of the polytetrapeptide of elastin: A polymer model for the $\beta$-turn. Biochem. Biophys. Res. Commun. 1974, 61 (4), 1427-1433.

(50) Iizuka, E.; Yang, J. T. The Disordered and $\beta$ Conformations of Silk Fibroin in Solution. Biochemistry 1968, 7 (6), 2218-2228.

(51) Portnov Tanya, T. R. S. a. M. Z. Injectable hydrogel-based scaffolds for tissue engineering applications. Rev. Chem. Eng. 2017, 33 (1), 91-107.

(52) Betz, P.; Nerlich, A.; Wilske, J.; Tubel, J.; Penning, R.; Eisenmenger, W. Immunohistochemical localization of collagen types I and VI in human skin wounds. International journal of legal medicine 1993, 106 (1), 31-4.

(53) Ibáñez-Fonseca, A.; Ramos, T. L.; González de Torre, I.; Sánchez-Abarca, L. I.; Muntión, S.; Arias, F. J.; del Cañizo, M. C.; Alonso, M.; Sánchez-Guijo, F.; Rodríguez-Cabello, J. C. Biocompatibility of two model elastin-like recombinamer-based hydrogels formed through physical or chemical cross-linking for various applications in tissue engineering and regenerative medicine. J. Tissue Eng. Regener. Med. 2018, 12 (3), e1450.

(54) González de Torre, I.; Santos, M.; Quintanilla, L.; Testera, A.; Alonso, M.; Rodríguez Cabello, J. C. Elastin-like recombinamer catalyst-free click gels: Characterization of poroelastic and intrinsic viscoelastic properties. Acta Biomater. 2014, 10 (6), 2495-2505.

(55) Staubli, S. M.; Cerino, G.; Gonzalez De Torre, I.; Alonso, M.; Oertli, D.; Eckstein, F.; Glatz, K.; Rodríguez Cabello, J. C.; Marsano, A. Control of angiogenesis and host response by modulating the cell adhesion properties of an Elastin-Like Recombinamer-based hydrogel. Biomaterials 2017, 135, 30-41.

(56) Hayes, W. C.; Bodine, A. J. Flow-independent viscoelastic properties of articular cartilage matrix. J. Biomech. 1978, 11 (8), 407419.

(57) Han, L.; Frank, E. H.; Greene, J. J.; Lee, H.-Y.; Hung, H.; Grodzinsky, A. J.; Ortiz, C. Time-Dependent Nanomechanics of Cartilage. Biophys. J. 2011, 100 (7), 1846-1854.
(58) Lee, B.; Han, L.; Frank, E. H.; Chubinskaya, S.; Ortiz, C.; Grodzinsky, A. J. Dynamic mechanical properties of the tissueengineered matrix associated with individual chondrocytes. J. Biomech. 2010, 43 (3), 469.

(59) Spiller, K. L.; Laurencin, S. J.; Charlton, D.; Maher, S. A.; Lowman, A. M. Superporous hydrogels for cartilage repair: Evaluation of the morphological and mechanical properties. Acta Biomater. 2008, 4 (1), 17-25.

(60) Gonzalez de Torre, I.; Weber, M.; Quintanilla, L.; Alonso, M.; Jockenhoevel, S.; Rodriguez Cabello, J. C.; Mela, P. Hybrid elastinlike recombinamer-fibrin gels: physical characterization and in vitro evaluation for cardiovascular tissue engineering applications. Biomater. Sci. 2016, 4 (9), 1361-1370.

(61) Kretlow, J. D.; Klouda, L.; Mikos, A. G. Injectable matrices and scaffolds for drug delivery in tissue engineering. Adv. Drug Delivery Rev. 2007, 59 (4-5), 263-73.

(62) Annabi, N.; Nichol, J. W.; Zhong, X.; Ji, C.; Koshy, S.; Khademhosseini, A.; Dehghani, F. Controlling the porosity and microarchitecture of hydrogels for tissue engineering. Tissue Eng., Part B 2010, 16 (4), 371-83.

(63) Athanasiou, K. A.; Darling, E. M.; Hu, J. C. Articular Cartilage Tissue Engineering. Synthesis Lectures on Tissue Engineering 2009, 1 (1), $1-182$.

(64) Guilak, F.; Estes, B. T.; Diekman, B. O.; Moutos, F. T.; Gimble, J. M. 2010 Nicolas Andry Award: Multipotent Adult Stem Cells from Adipose Tissue for Musculoskeletal Tissue Engineering. Clin. Orthop. Relat. Res. 2010, 468 (9), 2530-2540.

(65) Mouser, V. H. M.; Dautzenberg, N. M. M.; Levato, R.; van Rijen, M. H. P.; Dhert, W. J. A.; Malda, J.; Gawlitta, D. Ex vivo model unravelling cell distribution effect in hydrogels for cartilage repair. Altex 2018, 35 (1), 65-76.

(66) Mouw, J. K.; Case, N. D.; Guldberg, R. E.; Plaas, A. H. K.; Levenston, M. E. Variations in matrix composition and GAG fine structure among scaffolds for cartilage tissue engineering. Osteoarthritis and Cartilage 2005, 13 (9), 828-836.

(67) Pfeiffer, E.; Vickers, S. M.; Frank, E.; Grodzinsky, A. J.; Spector, $M$. The effects of glycosaminoglycan content on the compressive modulus of cartilage engineered in type II collagen scaffolds. Osteoarthritis and Cartilage 2008, 16 (10), 1237-1244.

(68) Fermor, H. L.; McLure, S. W.; Taylor, S. D.; Russell, S. L.; Williams, S.; Fisher, J.; Ingham, E. Biological, biochemical and biomechanical characterisation of articular cartilage from the porcine, bovine and ovine hip and knee. Bio-Med. Mater. Eng. 2015, 25 (4), 381-95.

(69) DeKosky, B. J.; Dormer, N. H.; Ingavle, G. C.; Roatch, C. H.; Lomakin, J.; Detamore, M. S.; Gehrke, S. H. Hierarchically designed agarose and poly(ethylene glycol) interpenetrating network hydrogels for cartilage tissue engineering. Tissue Eng., Part C 2010, 16 (6), $1533-42$.

(70) Knudson, C. B.; Knudson, W. Cartilage proteoglycans. Semin. Cell Dev. Biol. 2001, 12 (2), 69-78.

(71) T Nguyen, Q.; Hwang, Y.; C Chen, A.; Varghese, S.; Sah, R. Cartilage-like mechanical properties of poly (ethylene glycol)diacrylate hydrogels. Biomaterials 2012, 33, 6682-6690.

(72) Ahearne, M.; Kelly, D. J. A comparison of fibrin, agarose and gellan gum hydrogels as carriers of stem cells and growth factor delivery microspheres for cartilage regeneration. Biomed. Mater. (Bristol, U. K.) 2013, 8 (3), 035004. 